\title{
Current Perspectives on Phytomedicines targeting Cancer Stem Cells
}

\author{
Mrunmayee Saraff ${ }^{1}$, Rekha Gahtori ${ }^{2}$, Surya Tripathi ${ }^{3}$, Sugapriya Dhanasekaran ${ }^{4}$, Sanjay \\ Kumar $^{5}$, Soumya Pandit ${ }^{5}$, Dillip Bishi ${ }^{6}$, and Piyush Gupta ${ }^{5}$ \\ ${ }^{1}$ St Xavier's College \\ ${ }^{2}$ Kumaun University \\ ${ }^{3}$ National Institute of Technology Rourkela \\ ${ }^{4}$ Prince Sattam bin Abdulaziz University \\ ${ }^{5}$ Sharda University \\ ${ }^{6}$ Rama Devi Women's University
}

January 15, 2021

\begin{abstract}
Studies have established the presence of a small subpopulation of cells within tumor cells, known as cancer stem cells (CSCs). These cells have evidently been the reason for metastasis, chemotherapy or radiotherapy resistance and tumor relapses in several types of cancers. CSCs are prone to epithelial-to-mesenchymal transition (EMT), resulting in aggressive tumors. They modulate various pathways of molecular signaling, including Wnt, Hedgehog and Notch, thus increasing the stem-like characteristics. Elevated expression of ATP binding cassette (ABC) transporter efflux pump as well as suppression of apoptosis has also increased anti-cancer drug resistance. Plants are known to possess bioactive compounds that can modulate these key regulators and hence eliminate CSCs. This review aims to report and summarize preclinical studies about the effects of phytocompounds on CSCs of various tumors. Furthermore, clinical trials carried out for some of these phytoconstituents are reported. Thus, selectively targeting CSCs with plant extracts and herbal preparations may be a promising remedial strategy for cancer.
\end{abstract}

Current Perspectives on Phytomedicines targeting Cancer Stem Cells

Mrunmayee Saraff ${ }^{1}$, Rekha Gahtori ${ }^{2}$, Surya Kant Tripathi ${ }^{3}$, Sugapriya Dhanasekaran ${ }^{4}$, Sanjay Kumar $^{5}$, Soumya Pandit ${ }^{5}$, Dillip Kumar Bishi ${ }^{6}$, Piyush Kumar Gupta ${ }^{5 *}$

1. Department of Microbiology, St. Xavier's College (Autonomous), Mumbai - 400001, Maharashtra, India

2. Department of Biotechnology, Sir J. C. Bose Technical Campus, Kumaun University, Nainital - 263136, Uttarakhand, India

3. Cancer Drug Resistance Laboratory, Department of Life Science, National Institute of TechnologyRourkela - 769008, Odisha, India

4. Department of Medical Laboratory Sciences (Pathology), College of Applied Medical Sciences, Prince Sattam Bin Abdulaziz University, Wadi-Al Dawaser, Riyadh, Saudi Arabia

5. Department of Life Sciences, School of Basic Sciences and Research, Sharda University, Knowledge Park III, Greater Noida - 201310, Uttar Pradesh, India

6. Department of Biotechnology, Rama Devi Women's University, Bhubaneswar-751022, Odisha, India

*Corresponding Author - 
Dr. Piyush Kumar Gupta

Assistant Professor

Department of Life Sciences

School of Basic Sciences and Research

Sharda University, Knowledge Park III

Greater Noida - 201310, Uttar Pradesh, India

Email id.:piyush.kumar1@sharda.ac.in

Mobile no. +917017866485

\begin{abstract}
Studies have established the presence of a small subpopulation of cells within tumor cells, known as cancer stem cells (CSCs). These cells have evidently been the reason for metastasis, chemotherapy or radiotherapy resistance and tumor relapses in several types of cancers. CSCs are prone to epithelial-to-mesenchymal transition (EMT), resulting in aggressive tumors. They modulate various pathways of molecular signaling, including Wnt, Hedgehog and Notch, thus increasing the stem-like characteristics. Elevated expression of ATP binding cassette (ABC) transporter efflux pump as well as suppression of apoptosis has also increased anti-cancer drug resistance. Plants are known to possess bioactive compounds that can modulate these key regulators and hence eliminate CSCs. This review aims to report and summarize preclinical studies about the effects of phytocompounds on CSCs of various tumors. Furthermore, clinical trials carried out for some of these phytoconstituents are reported. Thus, selectively targeting CSCs with plant extracts and herbal preparations may be a promising remedial strategy for cancer.

Key words- Phytomedicine; Cancer stem cell; EMT; Signaling pathway; Preclinical; Clinical research

\section{Highlights}

- CSCs leads to tumor heterogeneity and responsible for recurrence of treated tumors

- CSCs can be targeted via several signaling pathways

- We discuss preclinical studies on phytocompounds targeted key regulators of these pathways

- Clinical trials on phytocompounds targeting recurrent cancer are summarized
\end{abstract}

\title{
1. Introduction
}

Cancer is a deadly disease affecting the worldwide population. The major problem in cancer treatment is the drug resistance and one of the factors responsible for it is CSC (Holohan et al., 2013; Torquato et al., 2017) . CSCs are those cancerous cells that possess a unique capacity for self-renewal which makes them immortal(Chang, 2016). Pluripotency-associated transcription factors such as Oct 4, Sox-2, and Nanog play essential roles in maintenance of stemness in these CSCs (Yun et al., 2017) . Due to this stemness, CSCs lead to tumor heterogeneity and aggressiveness which eventually leads to metastasis (Kusoglu \& Biray Avc1, 2019). CSCs also cause the dormancy of the tumors resulting in treatment resistance and increased chance of relapse (Steinbichler et al., 2018). CSCs are accountable for initiation of cancer as well as for recurrence of treated tumors and hence have become crucial focal point in cancer research during recent years (Cianciosi et al., 2018; Oh et al., 2016) .

CSCs account for EMT, due to which the cells become more motile and invasive. The reversal of EMT additionally contributes to tumor proliferation. Aberration of various molecular and cellular signaling pathways as well as altered metabolism of CSCs further exacerbate the tumor heterogeneity. Thus, CSCs play an active role in cancer dissemination (Yadav \& Desai, 2019) .

Radiotherapy and chemotherapy are the conventional treatment methods for any type of cancer. However, recently, several plants and plant-based compounds are found to be attractive candidates in cancer therapy, 
owing to their lower toxicity and higher selectivity against cancer cells(Torquato et al., 2017) . Phytomedicines are plant-based compounds that are obtained either in isolated form or as a mixture of different secondary metabolites to prevent and cure different diseases(Bonam et al., 2018) .

Phytomedicines possess various vitamins, minerals, and antioxidant compounds due to which they exhibit a prospective to treat cancer(Bonam et al., 2018). Herbal medicines and their bioactive constituents have been used and tested for several past years. Subsequently, it has been found that they depict antitumor activity by modulating one of the signaling pathways, targeting efflux pump ABC transporters or by inducing apoptosis and cell cycle arrest. Utilization of plant natural product as anti-CSC agents has gained momentum recently. Many studies have shown that medicinal plants, herbs or their bioactive compounds reduce the stem-like characteristics of CSCs. They interfere with EMT-genes, decrease invasiveness and migratory properties(Hermawan \& Putri, 2018). Here, we focused on recent updates in discovery and use of phytomedicines against CSCs.

\section{Cancer Stem Cells (CSCs)}

CSCs are known to express certain specific antigens which act as molecular markers and help in their validation and identification as shown in Figure 1. These markers can be targeted for site-specific delivery of phytocompounds using nanocarriers(Gupta et al., 2020). In Table 1 we summarize CSC markers for various cancer types (Gupta et al., 2020, Makena et al., 2020) .

Table 1. Markers of Cancer stem cell.

\begin{tabular}{lll}
\hline Cancer Type & CSC Markers & Reference \\
\hline Leukemia & CD34+CD38- & (Leong et al., 2017) \\
Breast cancer & CD44+/ESA+/CD24-/ALDH1+/ ABCG2+/ EpCAM+/CXCR4 & (Hermawan \& Putri, 20 \\
Brain tumour & CD133+/ CD90+/ ALDH1+ & (Kaur et al., 2018) \\
Pancreatic cancer & CD44+/CD24+/ESA+/ CD133+/Bmi1/ALDH1+/ABCG2+/ CXCR4 & (S.-H. Li et al., 2013) \\
Colon cancer & CD133+/ALDH1+/CD44+/EpCAM & (Soltanian et al., 2018) \\
Liver cancer & CD133+/CD90+/ CD44+/ ABCG2+/ EpCAM+/CD13+ & (Yen et al., 2018) \\
Prostate cancer & CD44+/CD133+/ ALDH1+/ Bmi1 & (Kamalidehghan et al., \\
Lung cancer & CD133+/CD117+/ ALDH1+/ ABCG2+/EpCAM & (Bhummaphan et al., 2 \\
Ovarian cancer & CD133+/CD44+/CD117+/ALDH1+/ABCG2+ & (Torquato et al., 2017) \\
Stomach cancer & CD44+/CD133+ & (Oh et al., 2016) \\
Nasopharyngeal cancer & CD44+/CD133+/ALDH1+/ ABCG2+/ Bmi1 & (S.-C. Liu et al., 2019) \\
Renal cancer & CD105+ & (Kaur et al., 2018) \\
Oral cancer & CD44+/ ALDH1+/CD117+/ Bmi1 & (Jobani et al., 2018) \\
Melanoma & ABCB5+/ALDH1+/CD133+/CD44+/CD117+ \\
Glioblastoma & CD133+/CD44+/ Bmi1 & (Su et al., 2019) \\
\hline
\end{tabular}

ABCB5: ATP-binding cassette sub-family B member 5; ABCG2: ATP-binding cassette sub-family G member 2; ALDH1: aldehyde dehydrogenase 1A1; Bmi1: B cell-specific Moloney murine leukemia virus integration site 1; CD24: heat stable antigen; CD34: hematopoietic progenitor cell antigen; CD38: cyclic ADP ribose hydrolase; CD44: hyaluronate receptor; CD90: Thymocyte differentiation antigen-1; CD133: prominin-1; CD117: c-kit ; CSC: cancer stem cell; CXCR4: receptor for chemokine; EpCAM: epithelial cell adhesion molecule; ESA: epithelial surface antigen

Tumorigenesis has been explained by two different models, namely the stochastic model and the hierarchical model (CSC model). According to stochastic model, transformation of somatic cells leads to generation of tumor. In contrast, the hierarchical model states that CSCs are the origin of tumor formation (Barbato et al., 2019; Batlle \& Clevers, 2017) . CSCs can themselves be derived clonally via cell division (symmetric or asymmetric) of cancer progenitor cells or transformed stem cells (Oh et al., 2016). Overall, CSCs give rise to aggressively metastasizing tumors. 
Tumor cells are known to undergo phenotypic alteration as a consequence of EMT during cancer progression. In EMT, the epithelial cells develop the traits of mesenchymal cells which is characterized by E-cadherin downregulation and N-cadherin upregulation, which in turn is regulated by numerous transcription factors such as Snail, Slug and Twist(Nistico et al., 2012; Salehi et al., 2019, Sinha et al., 2019). EMT causes the apical-basal polar epithelial cells to depict front-rear polarity of mesenchymal cells, due to which they show enhanced motility and migration properties (Antony et al., 2019) .

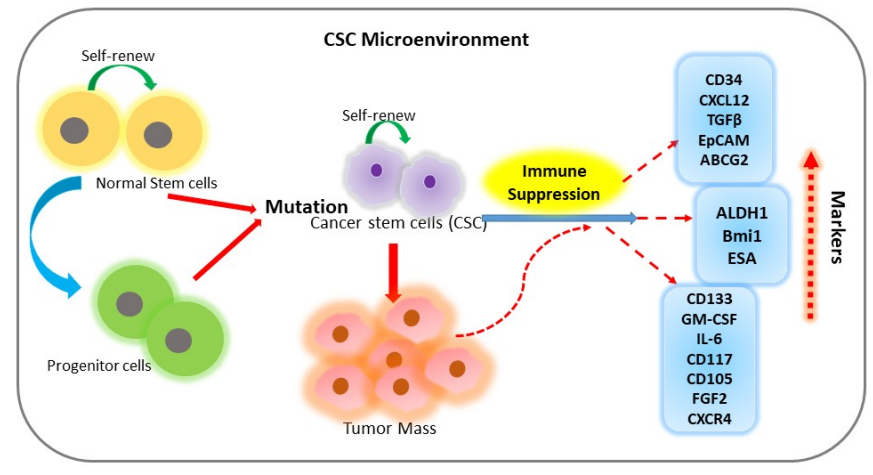

Figure 1. Cancer stem cell and their overexpressed markers.

In cancer metastasis, generally five steps are described: invasion, intravasation, transport, extravasation, and colonization (Tsai \& Yang, 2013) . EMT is vital for intravasation and extravasation. However, a loss of EMT induction signaling is necessary to achieve proliferation of cancer cells. This process of EMT reversal, called mesenchymal-epithelial transition (MET) that helps in tumor growth(Chang, 2016; Tsai \& Yang, 2013) . As an outcome of the whole transition process, the tumor cells become more invasive, metastasize and depict resistance to chemotherapy and radiotherapy (Naveen et al., 2016) .

Regulation of CSCs is brought about by several different mechanisms such as Janus-activated kinase/signal transducer and activator of transcription (JAK/STAT), nuclear factor-kappa B (NF- $\varkappa$ B), phosphatidylinositol 3-kinase-Akt (PI3K-Akt), Hedgehog, Wnt, and Notch signaling pathways that are discussed below and have shown to mediate the stemness of CSCs as shown in Figure 2 (Gupta et al., 2020, Matsui, 2016) 

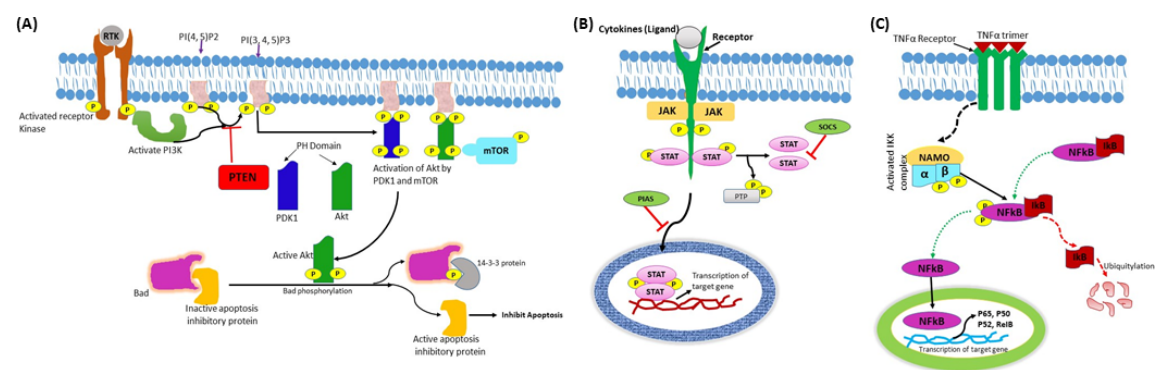

(D)

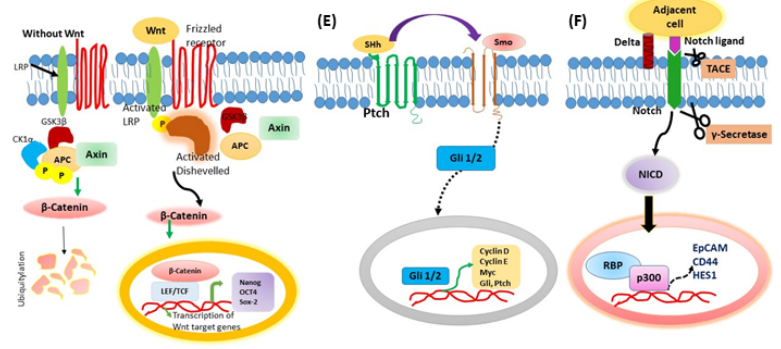

Figure 2. Stemness of CSCs mediated by various signaling pathways like (A) PI3K-Akt, (B) JAK/STAT, (C)NF- $\varkappa \mathrm{B}$, (D) Wnt/ $\beta$-catenin, (E) Hedgehog, and(F) Notch pathways.

\section{JAK/STAT pathway}

Ligand (interleukins, growth factors or hormones) binding to receptors, brings together the two associated JAKs so that they can phosphorylate each other on tyrosines to become fully activated, after which they phosphorylate the receptors to generate binding sites for STAT proteins. The JAKs further phosphorylate the STAT proteins, which dissociate from the receptor to form dimers and enter the nucleus to control gene expression. Overexpression of several genes like IL-6and CSF2, as well as highly activated STAT1or STAT3 constitute towards the aberration of this pathway in CSCs (Stine \&Matunis, 2013) .

\section{PI3K-Akt pathway}

On binding of ligand to receptor tyrosine kinases, the plasma-membrane-bound enzyme phosphoinositide 3-kinase (PI 3-kinase) is activated and converts phosphatidylinositol(3,4)-bis-phosphate (PIP2) to phosphatidylinositol(3,4,5)-trisphosphate (PIP3). PIP3 serves as a docking site for protein kinase B (PKB) (also called Akt). PKB is then phosphorylated and activated by mammalian target of rapamycin (mTOR) and the phosphoinositide-dependent kinase (PDK1). Activated PKB further brings about inhibition of apoptosis by phosphorylating Bad. PTEN, a phosphatase, acts as a negative regulator of the process, causing dephosphorylation of PIP3 to PIP2. Constitutive activation of PKB or inactivation of PTEN has been observed to be the cause for tumor generation in various cancers (Hemmings \& Restuccia, 2012) .

\section{$\mathrm{N} \Phi-\varkappa \mathrm{B} \pi \alpha \tau \eta \omega \alpha \psi$}

$\mathrm{NF}-\varkappa \mathrm{B}$ pathway can be either canonical or non-canonical. In the canonical pathway, binding of ligands (IL-1 $\beta$ or bacterial cell wall components) to their respective receptors (IL-1 receptor or toll-like receptors), causes recruitment of adaptor proteins which in turn phosphorylate $\mathrm{IkB}$, marking it for ubiquitination and proteasome degradation. As a result, $\mathrm{NF}-\chi \mathrm{B}$ is released, which then translocates to the nucleus and facilitates gene transcription. The non-canonical pathway on the other hand is activated by receptor activator of NF$\chi \mathrm{B}$ (RANK) and CD40. The kinases then bring about phosphorylation and process p100/RelB dimers into p52/RelB dimers. NF- $x \mathrm{~B}$ is consequently released, translocates into nucleus and facilitates transcription (Hoesel\& Schmid, 2013) .

\section{Hedgehog pathway}


Sonic Hedgehog (SHh), Indian Hedgehog (IHh) and Desert Hedgehog (DHh) are the ligands and Patched 1 $(\mathrm{PTCH})$ is the cognate receptor involved in this pathway. When the receptor is unoccupied by the ligand, it functions as a constitutive inhibitor of a transmembrane protein Smoothened (Smo) and the target gene transcription is repressed by Gli repressor. On binding of ligand to Patched 1, the repression on Smoothened is released, allowing the Gli transcriptional activators to promote transcription of target genes (Kumar et al., 2018) .

\section{$\Omega \nu \tau / \beta-\varsigma \alpha \tau \varepsilon \nu \omega \nu \pi \alpha \tau \eta \omega \alpha \psi$}

Wnt pathway in essence comprises of canonical ( $\beta$-catenin dependent) and noncanonical ( $\beta$-cateninindependent) signaling pathway. Here, we focus on canonical pathway which is found to be implicated in survival of most of the CSCs. In canonical Wnt signaling pathway, in the absence of Wnt ligands (Wnt3a and Wnt1), $\beta$-catenin is phosphorylated due to its interaction with the destruction complex, which consists of the scaffold protein Axin, APC and GSK3 $\beta$ kinase and casein kinase (CK1 $\alpha)$. This phosphorylation brings about ubiquitination and degradation of $\beta$-catenin. On the other hand, the pathway is activated when Wnt ligands bind to Frizzled (Fzd) receptors and/or the low-density lipoprotein-related protein (LRP) co-receptors. As a result, Dishevelled (Dvl) proteins are recruited and Dvl polymers inactivate the destruction complex. This results in stabilization and accumulation of $\beta$-catenin which then translocates into the nucleus, binds to lymphoid enhancer factor (LEF)/T-cell factor (TCF) transcription factors, and facilitates transcription of various target genes (Zhan et al., 2017) .

\section{Notch pathway}

When Notch ligand (Delta-like-1, DLL3, DLL4, Jagged1, or JAG2) binds to its receptor (Notch1-4), ADAM/TACE and $\gamma$-secretase commence the proteolytic cleavage of the cytoplasmic domain of the receptor. This dual cleavage causes the release of Notch intracellular domain (NICD) into the cytoplasm. It then translocates to the nucleus and activates transcription of target genes via the CBF1, Suppressor of Hairless, LAG-1/recombination signal binding protein for immunoglobulin $\mathrm{k}$ J region (CSL/RBPJ) transcription factor (Karamboulas \& Ailles, 2013) .

\section{Preclinical research on phytomedicines targeting key regulators of anti-cancer drug resis- tance in CSCs}

CSCs contribute to drug resistance by regulation of EMT; elevated expression of ABC transporters, increase in aldehyde dehydrogenase (ALDH) enzymes, resistance to DNA damage and cell death, slow cycling of microRNAs and regulation of tumor microenvironment (Makena et al., 2020). Phytocompounds targeting either one of these key regulators of anti-cancer drug resistance (as shown in Figure 3 ) can prove to be useful in the elimination of CSCs and in improving the outcome of cancer disease treatment.

Curcumin is a dietary polyphenol extracted from turmeric rhizomes (Curcuma longa). It has been explored for past many years and considered to be a potential anti-cancer therapeutic agent. Recently, reports have revealed that curcumin targets CSCs in breast, thyroid, and brain cancers. It can act in different ways but converges to a final outcome of reducing the tumor cells. In a study, curcumin was reported to downregulate EMT (Vimentin, Fibronectin, $\beta$-catenin,) and stemness (Sox-2, Nanog, and Oct-4) markers whereas in another study it reduced the expression of ABC transporters in breast CSCs (Hu et al., 2019; Zhou et al., 2015) . It dysregulated JAK/STAT3 signaling pathway in papillary thyroid CSCs (Khan et al., 2020) . Also, recently, in order to boost the stability and water solubility, thus improving the drug's permeability and antitumor activity, curcumin liposome was constructed. As a result, its apoptotic effect on glioblastoma stem cells was established (Y. Wang et al., 2017) .

Ovatodiolide is a macrocyclic diterpenoid isolated from Anisomeles indica, whose effect against different cancers like glioblastoma, nasopharyngeal carcinoma and oral cancer was studied in vitro andin vivo and its potential therapeutic properties were established. It was found that ovatodiolide reduces stemness markers (CD44, CD133, Sox2, Klf4, Nanog and Oct-4) and decreases expression of EMT genes. It modulated JAK2/STAT3 signaling pathway by inhibiting either JAK2 or STAT3; thereby dysregulating transcription 
of genes. Also, it induced apoptosis of tumor cells. Furthermore, in vivostudies on oral carcinoma mouse xenografts were carried out and promising results were obtained. Treatment of nude mice (previously injected with SAS cells) with $3.6 \mathrm{mg} / \mathrm{kg}$ ovatodiolide depicted 2.2 -folds lesser tumor growth compared to the untreated mice (Lin et al., 2018; S.-C. Liu et al., 2019; Su et al., 2019) .

Stem extract of Dendrobium venustum containing Lusianthridin downregulated Src-STAT3-c-Myc pathway and suppressed CD133, ABCG2, and ALDH1A1 stemness markers which induced apoptosis in lung CSCs(Bhummaphan et al., 2019) . Polygonum cuspidatum root extract which mainly comprises of 2Ethoxystypandrone showed inhibition of STAT3 signaling in hepatocellular carcinoma (W. Li et al., 2019)

Most of the compounds that have been evaluated have shown to target cell death/ apoptosis pathway, while some also contribute to cell cycle arrest. Fruit extract of Alstonia scholaris induced apoptosis in glioma stem cells, owing to the presence of two nor-monoterpenoid indole alkaloids, Scholarisine Q(1) and R(2) (B. Wang et al., 2018) . Similarly, bark extract of Walsura pinnata Hassk and rhizome extract of Costus speciosus induced apoptosis in leukemia and prostate cancer cells respectively (Elkady, 2019; Leong et al., 2017) . Viola odorata, a plant possessing active components such as saponin, salicylic acid derivatives, glycosides, alkaloids, anthocyanidins and cyclotides was shown to induce apoptosis and reduce migration and growth of breast CSC (Yousefnia et al., 2020). Berberis is a plant possessing bioactive compound berberine, which reportedly causes G0-G1 arrest. It was found to be effective in reducing stemness and cell migration in neuroblastoma and prostate CSCs respectively (El-Merahbi et al., 2014; Naveen et al., 2016) .

Targeting stemness markers and EMT genes thus presents with the hope to decrease CSCs. Cinnamic acid was shown to decrease stemness in colon CSCs (Soltanian et al., 2018) . Carnosol modulated EMT genes and induced apoptosis in glioblastoma CSCs (Giacomelli et al., 2017) . Likewise, N-butylidenephthalide, a bioactive component of Angelica Sinensis induced apoptosis in human bladder cancer cells and supressed tumor in BFTC-xenograft animal models (100 and $200 \mathrm{mg} / \mathrm{kg}$ dose) (Chiu et al., 2017) .

Phenethyl isothiocyanate, a component of cruciferous vegetables like broccoli and water cress promoted oxidative stress and downregulated cancer stemness genes in cervical and colon carcinomas respectively. A study reported that NOD-SCID mice injected with 10uM PEITC pre-treated HeLa CSCs yielded lower tumor volume compared to the control group (untreated HeLa CSCs). In another study, nude mice were treated with $20 \mathrm{mg} / \mathrm{kg}$ PEITC after EpCAM+ cell inoculation to determine whether PEITC suppresses CSCs in vivo and reduction in tumor growth was observed (Upadhyaya et al., 2019; Yun et al., 2017) .

Rhizome extract of Atractylodes macrocephala Koidz downregulated AKT/mTOR pathway and brought about alteration in glucose metabolism and stem-like behaviour in colon cancer cell line. Subsequently, 25 $\mathrm{mg} / \mathrm{kg}$ and $75 \mathrm{mg} / \mathrm{kg}$ Atractylenolide- 1 inhibited colorectal tumor progression in xenografted nude mice (K. Wang et al., 2020) . Similarly, total flavonoids of Fructus Viticis modulated AKT/mTOR pathway and stemness characteristics in lung CSCs (Cao et al., 2016) .

Allicin commonly found in garlic and it was evaluated as a promising compound for treatment of melanoma cells (Jobani et al., 2018). Shikonin, a natural derivative of naphthoquinone, found in the root tissues of the traditional Chinese medical (TCM) herb Lithospermum erythrorhizon was proven to be effective against glioblastoma stem cells (J. Liu et al., 2015) . An extract of herbal mixture (H3) consisting of 3 oriental herbal plants (Meliae fructus, Cinnamon bark and Sparganium rhizome) was investigated for anticancer activity in vitro and in vivo (200 $\mathrm{mg} / \mathrm{kg}$ dose of $\mathrm{H} 3$ used) and was found to be a promising therapeutic agent(Pak et al., 2016) . 


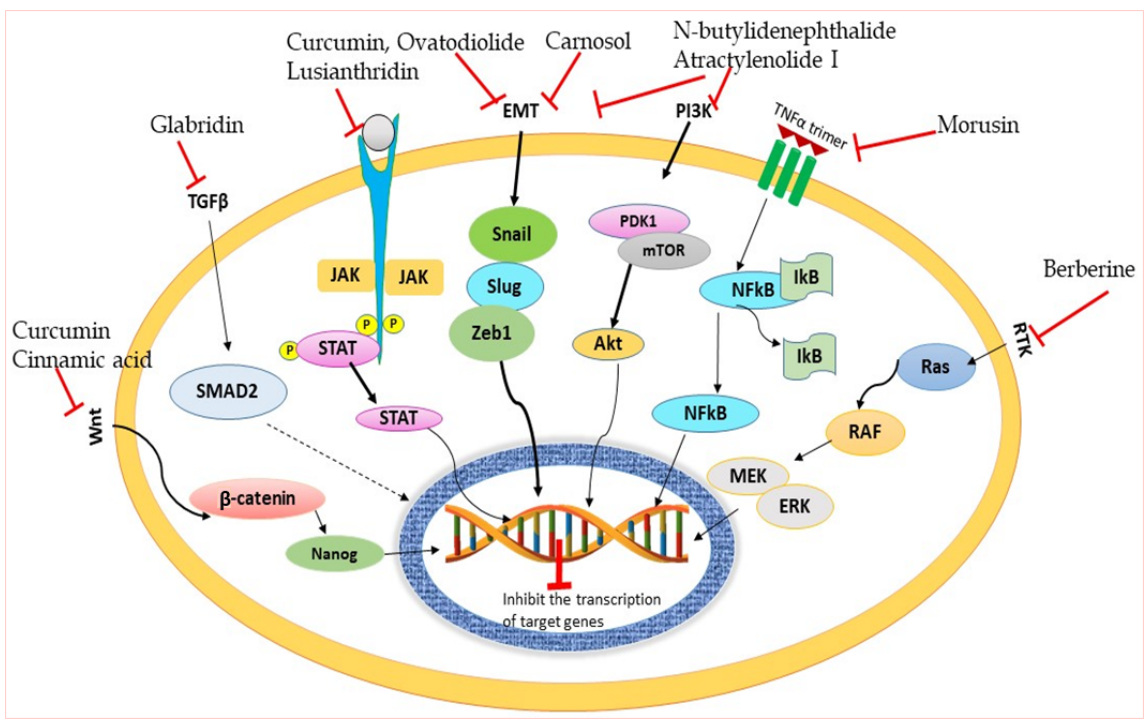

Figure 3. Phytocompounds targeting key regulators of anti-cancer drug resistance in CSCs such as Curcumin, Cinnamic acid: Wnt; Glabridin: SMAD2; Curcumin, Ovatodiolide, Lusianthridin: JAK/STAT; Ovatodiolide, Carnosol, N-butylidenephthalide: EMT; N-butylidenephthalide, Atractylenolide I: PI3K/Akt; Morusin: NF- $x$ B; Berberine: Ras/RAF.

Table 2. Phytocompounds targeting regulators of anti-cancer drug resistance in CSCs.

\begin{tabular}{|c|c|c|c|c|c|c|}
\hline $\begin{array}{l}\text { Plant } \\
\text { source }\end{array}$ & Extract & $\begin{array}{l}\text { Bioactive } \\
\text { compound }\end{array}$ & $\begin{array}{l}\text { Mode of } \\
\text { action }\end{array}$ & $\begin{array}{l}\text { In vivo } \\
\text { Dose }\end{array}$ & $\begin{array}{l}\text { Cell line/ } \\
\text { Model }\end{array}$ & References \\
\hline $\begin{array}{l}\text { Alstonia } \\
\text { scholaris } \\
\text { Anisomeles } \\
\text { indica }\end{array}$ & Fruit extract & $\begin{array}{l}\text { Scholarisine } \\
\mathrm{Q}(1) \text { and } \mathrm{R}(2) \\
\text { Ovatodiolide } \\
\text { (Ova) }\end{array}$ & $\begin{array}{l}\text { Induction of } \\
\text { apoptosis } \\
\text { Induction of } \\
\text { apoptosis } \\
\text { Modulation of } \\
\text { EMT process } \\
\text { Downregula- } \\
\text { tion of CD44, } \\
\text { CD133, Sox2, } \\
\text { and Oct-4 } \\
\text { Dysregulation } \\
\text { of } \\
\text { JAK2/STAT3 } \\
\text { pathway }\end{array}$ & $\overline{-}$ & $\begin{array}{l}\text { Glioma stem } \\
\text { cell lines } \\
\text { Glioblastoma } \\
\text { cell line }\end{array}$ & $\begin{array}{l}\text { Wang et al., } \\
2018 \\
\text { Su et al., } 2019\end{array}$ \\
\hline
\end{tabular}




\begin{tabular}{|c|c|c|c|c|c|c|}
\hline $\begin{array}{l}\text { Plant } \\
\text { source }\end{array}$ & Extract & $\begin{array}{l}\text { Bioactive } \\
\text { compound }\end{array}$ & $\begin{array}{l}\text { Mode of } \\
\text { action }\end{array}$ & $\begin{array}{l}\text { In vivo } \\
\text { Dose }\end{array}$ & $\begin{array}{l}\text { Cell line/ } \\
\text { Model }\end{array}$ & References \\
\hline & & & $\begin{array}{l}\text { Induction of } \\
\text { apoptosis } \\
\text { Downregula- } \\
\text { tion of Sox-2 } \\
\text { and Oct-4 } \\
\text { Increase of } \\
\text { E-cadherin } \\
\text { Dysregulation } \\
\text { of } \\
\text { JAK2/STAT3 } \\
\text { pathway }\end{array}$ & 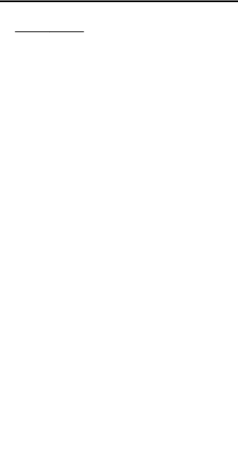 & $\begin{array}{l}\text { Nasopharyngeal } \\
\text { carcinoma cell } \\
\text { line }\end{array}$ & Liu et al., 2019 \\
\hline & & & $\begin{array}{l}\text { Induction of } \\
\text { apoptosis } \\
\text { Downregula- } \\
\text { tion of CD133, } \\
\text { Klf4, Oct4, } \\
\text { Nanog and } \\
\text { JARID1B } \\
\text { Dysregulation } \\
\text { of } \\
\text { JAK2/STAT3 } \\
\text { pathway }\end{array}$ & $3.6 \mathrm{mg} / \mathrm{kg}$ & $\begin{array}{l}\text { Oral CSCs } \\
\text { and xenograft } \\
\text { mouse models }\end{array}$ & Lin et al., 2018 \\
\hline \multirow[t]{2}{*}{$\begin{array}{l}\text { Cruciferous } \\
\text { vegetables } \\
\text { (Broccoli, } \\
\text { watercress, } \\
\text { cabbage) }\end{array}$} & - & $\begin{array}{l}\text { Phenethyl } \\
\text { isothiocyanate } \\
\text { (PEITC) }\end{array}$ & $\begin{array}{l}\text { Downregulation } \\
\text { of Oct4, } \\
\text { Nanog, and } \\
\text { Sox-2 }\end{array}$ & $20 \mathrm{mg} / \mathrm{kg}$ & $\begin{array}{l}\text { Colon cancer } \\
\text { cells and } \\
\text { mouse } \\
\text { xenograft } \\
\text { models }\end{array}$ & $\begin{array}{l}\text { Yun et al., } \\
2017\end{array}$ \\
\hline & & & $\begin{array}{l}\text { Promotion of } \\
\text { oxidative } \\
\text { stress } \\
\text { Suppression of } \\
\text { Sp1 } \\
\text { transcription } \\
\text { factor }\end{array}$ & $10 \mu \mathrm{M}$ & $\begin{array}{l}\text { Cervical CSCs } \\
\text { and xenotrans- } \\
\text { planted } \\
\text { NOD-SCID } \\
\text { mouse model }\end{array}$ & $\begin{array}{l}\text { Upadhyaya et } \\
\text { al., } 2019\end{array}$ \\
\hline $\begin{array}{l}\text { Atractylodes } \\
\text { macrocephala } \\
\text { Koidz }\end{array}$ & $\begin{array}{l}\text { Rhizome } \\
\text { extract }\end{array}$ & $\begin{array}{l}\text { Atractylenolide } \\
\text { I (ATL-1) }\end{array}$ & $\begin{array}{l}\text { Downregulation } \\
\text { of the phos- } \\
\text { phorylation of } \\
\text { proteins } \\
\text { related to the } \\
\text { AKT/mTOR } \\
\text { pathway } \\
\text { Alteration of } \\
\text { apoptosis, } \\
\text { glucose } \\
\text { metabolism, } \\
\text { and stem-like } \\
\text { behaviour }\end{array}$ & $\begin{array}{l}25 \mathrm{mg} / \mathrm{kg} \text { and } \\
75 \mathrm{mg} / \mathrm{kg}\end{array}$ & $\begin{array}{l}\text { Colon cancer } \\
\text { cell lines and } \\
\text { mouse } \\
\text { xenograft } \\
\text { model }\end{array}$ & $\begin{array}{l}\text { Wang et al., } \\
2020\end{array}$ \\
\hline
\end{tabular}




\begin{tabular}{|c|c|c|c|c|c|c|}
\hline $\begin{array}{l}\text { Plant } \\
\text { source }\end{array}$ & Extract & $\begin{array}{l}\text { Bioactive } \\
\text { compound }\end{array}$ & $\begin{array}{l}\text { Mode of } \\
\text { action }\end{array}$ & $\begin{array}{l}\text { In vivo } \\
\text { Dose }\end{array}$ & $\begin{array}{l}\text { Cell line/ } \\
\text { Model }\end{array}$ & References \\
\hline $\begin{array}{l}\text { Fructus viticis } \\
\text { (TCM) }\end{array}$ & 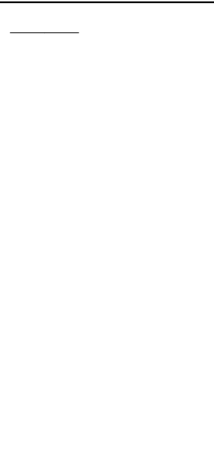 & Flavonoids & $\begin{array}{l}\text { Decrease the } \\
\text { phosphoryla- } \\
\text { tion level of } \\
\text { Akt Downreg- } \\
\text { ulation of } \\
\text { CD133, CD44 } \\
\text { and ALDH1, } \\
\text { Bmi1, Nanog } \\
\text { and OCT4, } \\
\text { Twist1 and } \\
\text { Snail1 }\end{array}$ & 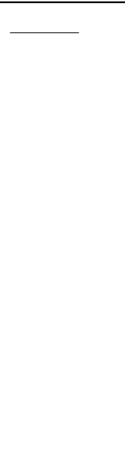 & Lung CSCs & $\begin{array}{l}\text { Cao et al., } \\
2016\end{array}$ \\
\hline Pigeon pea & & $\begin{array}{l}\text { Cajaninstilbene } \\
\text { acid } \\
\text { derivatives }\end{array}$ & $\begin{array}{l}\text { Cytotoxic } \\
\text { (pathway not } \\
\text { deduced) }\end{array}$ & $\longrightarrow$ & $\begin{array}{l}\text { Breast cancer } \\
\text { cell line }\end{array}$ & Seo et al., 2015 \\
\hline $\begin{array}{l}\text { Berberis } \\
\text { libanotica } \\
\text { Ehrenb }\end{array}$ & Root extract & & $\begin{array}{l}\text { G0-G1 arrest } \\
\text { Inhibition of } \\
\text { cellular } \\
\text { migration and } \\
\text { sphere } \\
\text { formation }\end{array}$ & & Prostate CSCs & $\begin{array}{l}\text { El-Merahbi et } \\
\text { al., } 2014\end{array}$ \\
\hline $\begin{array}{l}\text { Berberis, } \\
\text { Arcangelisia, } \\
\text { Hydrastis }\end{array}$ & - & Berberine & $\begin{array}{l}\text { G0/G1 cell } \\
\text { cycle arrest } \\
\text { Cancer } \\
\text { stemness } \\
\text { inhibition } \\
\text { (attenuation of } \\
\text { CD133, } \\
\text { ß-catenin, } \\
\text { n-myc, sox2, } \\
\text { notch2 and } \\
\text { nestin) EMT } \\
\text { reversal by } \\
\text { downregula- } \\
\text { tion of } \\
\text { PI3/Akt and } \\
\text { Ras-Raf-ERK } \\
\text { signaling. }\end{array}$ & - & $\begin{array}{l}\text { Neuroblastoma } \\
\text { cells }\end{array}$ & $\begin{array}{l}\text { Naveen et al., } \\
2016\end{array}$ \\
\hline
\end{tabular}




\begin{tabular}{|c|c|c|c|c|c|c|}
\hline $\begin{array}{l}\text { Plant } \\
\text { source }\end{array}$ & Extract & $\begin{array}{l}\text { Bioactive } \\
\text { compound }\end{array}$ & $\begin{array}{l}\text { Mode of } \\
\text { action }\end{array}$ & $\begin{array}{l}\text { In vivo } \\
\text { Dose }\end{array}$ & $\begin{array}{l}\text { Cell line/ } \\
\text { Model }\end{array}$ & References \\
\hline $\begin{array}{l}\text { Dendrobium } \\
\text { venustum }\end{array}$ & Stem extract & Lusianthridin & $\begin{array}{l}\text { Downregulation } \\
\text { of Src-STAT3- } \\
\text { c-Myc } \\
\text { pathways } \\
\text { Pro-survival } \\
\text { suppression } \\
\text { and } \\
\text { pro-apoptotic } \\
\text { induction } \\
\text { Abolishment } \\
\text { of stemness } \\
\text { (decrease in } \\
\text { CD133, } \\
\text { ABCG2, and } \\
\text { ALDH1A1) }\end{array}$ & 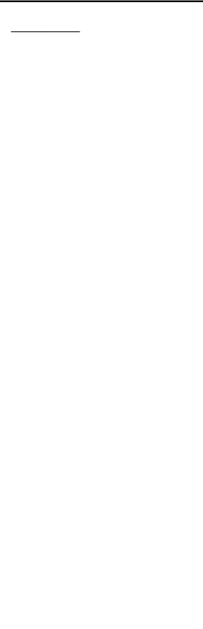 & Lung CSCs & $\begin{array}{l}\text { Bhummaphan } \\
\text { et al., } 2019\end{array}$ \\
\hline \multirow[t]{4}{*}{$\begin{array}{l}\text { Curcuma longa } \\
\text { (Turmeric) }\end{array}$} & - & Curcumin & $\begin{array}{l}\text { Downregulation } \\
\text { of expression } \\
\text { of Vimentin, } \\
\text { Fibronectin, } \\
\beta \text {-catenin, and } \\
\text { upregulation } \\
\text { of E-cadherin } \\
\text { Decreased } \\
\text { expression of } \\
\text { Sox-2, Nanog } \\
\text { and Oct-4 }\end{array}$ & - & Breast CSCs & Hu et al., 2019 \\
\hline & & Curcumin & $\begin{array}{l}\text { Reduction in } \\
\text { the expression } \\
\text { of ABC } \\
\text { transporters } \\
\text { ABCG } 2 \text { and } \\
\text { ABCC1 }\end{array}$ & - & Breast CSCs & $\begin{array}{l}\text { Zhou et al., } \\
2015\end{array}$ \\
\hline & & Curcumin & $\begin{array}{l}\text { Induction of } \\
\text { apoptosis } \\
\text { Dysregulation } \\
\text { of } \\
\text { JAK/STAT3 } \\
\text { signaling } \\
\text { pathway }\end{array}$ & - & $\begin{array}{l}\text { Papillary } \\
\text { thyroid CSCs }\end{array}$ & $\begin{array}{l}\text { Khan et al., } \\
2020\end{array}$ \\
\hline & & Curcumin & $\begin{array}{l}\text { Induction of } \\
\text { apoptosis }\end{array}$ & $5 \mathrm{mg} / \mathrm{kg}$ & $\begin{array}{l}\text { Glioblastoma } \\
\text { stem cells and } \\
\text { mouse models }\end{array}$ & $\begin{array}{l}\text { Wang et al., } \\
2017\end{array}$ \\
\hline $\begin{array}{l}\text { Walsura } \\
\text { pinnata Hassk }\end{array}$ & Bark extract & $\begin{array}{l}\text { Betulonic acid } \\
\text { (BA) }\end{array}$ & $\begin{array}{l}\text { Induction of } \\
\text { intrinsic } \\
\text { apoptosis }\end{array}$ & $\begin{array}{l}18,36 \text { or } 54 \\
\mu \mathrm{M}\end{array}$ & $\begin{array}{l}\text { Leukaemia } \\
\text { stem cells and } \\
\text { xeno- } \\
\text { transplanted } \\
\text { zebrafish } \\
\text { Model }\end{array}$ & $\begin{array}{l}\text { Leong et al., } \\
2017\end{array}$ \\
\hline
\end{tabular}




\begin{tabular}{|c|c|c|c|c|c|c|}
\hline $\begin{array}{l}\text { Plant } \\
\text { source }\end{array}$ & Extract & $\begin{array}{l}\text { Bioactive } \\
\text { compound }\end{array}$ & $\begin{array}{l}\text { Mode of } \\
\text { action }\end{array}$ & $\begin{array}{l}\text { In vivo } \\
\text { Dose }\end{array}$ & $\begin{array}{l}\text { Cell line/ } \\
\text { Model }\end{array}$ & References \\
\hline $\begin{array}{l}\text { Costus } \\
\text { speciosus }\end{array}$ & $\begin{array}{l}\text { Rhizome } \\
\text { extract }\end{array}$ & $\longrightarrow$ & $\begin{array}{l}\text { Induction of } \\
\text { apoptosis } \\
\text { G0/G1 and } \\
\text { G2/M arrest }\end{array}$ & $\longrightarrow$ & $\begin{array}{l}\text { Prostate } \\
\text { cancer cells }\end{array}$ & Elkady, 2019 \\
\hline Viola odorata & $\begin{array}{l}\text { Hydro- } \\
\text { alcoholic } \\
\text { extract of } \\
\text { aerial part }\end{array}$ & $\longrightarrow$ & $\begin{array}{l}\text { Induction of } \\
\text { apoptosis }\end{array}$ & $\longrightarrow$ & Breast CSCs & $\begin{array}{l}\text { Yousefnia et } \\
\text { al., } 2020\end{array}$ \\
\hline $\begin{array}{l}\text { Polygonum } \\
\text { cuspidatum }\end{array}$ & Root extract & $\begin{array}{l}2- \\
\text { Ethoxystypand }\end{array}$ & $\begin{array}{l}\text { Induction of } \\
\text { mepoptosis } \\
\text { Inhibition of } \\
\text { STAT3 } \\
\text { signaling }\end{array}$ & $\longrightarrow$ & $\begin{array}{l}\text { Hepatocellular } \\
\text { CSCs }\end{array}$ & Li et al., 2019 \\
\hline $\begin{array}{l}\text { Cinnammum } \\
\text { cassia } \\
\text { (Cinnamon) }\end{array}$ & - & Cinnamic acid & $\begin{array}{l}\text { Downregulation } \\
\text { of CSC- } \\
\text { associated } \\
\text { markers } \\
\text { (OCT4, } \\
\text { NANOG, } \\
\text { ABCB1, and } \\
\text { ALDH1A) and } \\
\text { the proportion } \\
\text { of CSCs (SP } \\
\text { cells, CD44, } \\
\text { and CD133 } \\
\text { positive cells) }\end{array}$ & $\longrightarrow$ & $\begin{array}{l}\text { Colon cancer } \\
\text { cell line }\end{array}$ & $\begin{array}{l}\text { Soltanian et } \\
\text { al., } 2018\end{array}$ \\
\hline $\begin{array}{l}\text { Glycyrrhiza } \\
\text { glabra } \\
\text { (Licorice) }\end{array}$ & & Glabridin & $\begin{array}{l}\text { Epigenetic } \\
\text { regulation } \\
\text { ofmiR- } \\
\text { 148a/SMAD2 } \\
\text { signaling }\end{array}$ & $20 \mathrm{mg} / \mathrm{kg}$ & $\begin{array}{l}\text { Breast cancer } \\
\text { cell lines and } \\
\text { mouse } \\
\text { xenograft } \\
\text { models }\end{array}$ & $\begin{array}{l}\text { Jiang et al., } \\
2016\end{array}$ \\
\hline $\begin{array}{l}\text { Morus } \\
\text { australis }\end{array}$ & & Morusin & $\begin{array}{l}\text { Induction of } \\
\text { apoptosis } \\
\text { Attenuation of } \\
\text { NF- } x \text { B activity }\end{array}$ & - & Cervical CSCs & $\begin{array}{l}\text { Wang et al., } \\
2013\end{array}$ \\
\hline $\begin{array}{l}\text { Lithospermum } \\
\text { erythrorhizon }\end{array}$ & $\longrightarrow$ & Shikonin & $\begin{array}{l}\text { Involvement of } \\
\text { JNK/c-Jun } \\
\text { pathway }\end{array}$ & $2 \mathrm{mg} / \mathrm{kg}$ & $\begin{array}{l}\text { Glioblastoma } \\
\text { stem cells and } \\
\text { xenografted } \\
\text { mice }\end{array}$ & Liu et al., 2015 \\
\hline $\begin{array}{l}\text { Rosmarinus } \\
\text { officinalis } \\
\text { (Rosemary) }\end{array}$ & $\longrightarrow$ & Carnosol & $\begin{array}{l}\text { Induction of } \\
\text { apoptosis via } \\
\text { p } 53 \text { functional } \\
\text { reactivation } \\
\text { Modulation of } \\
\text { EMT }\end{array}$ & - & $\begin{array}{l}\text { Glioblastoma } \\
\text { CSCs }\end{array}$ & $\begin{array}{l}\text { Giacomelli et } \\
\text { al., } 2017\end{array}$ \\
\hline
\end{tabular}




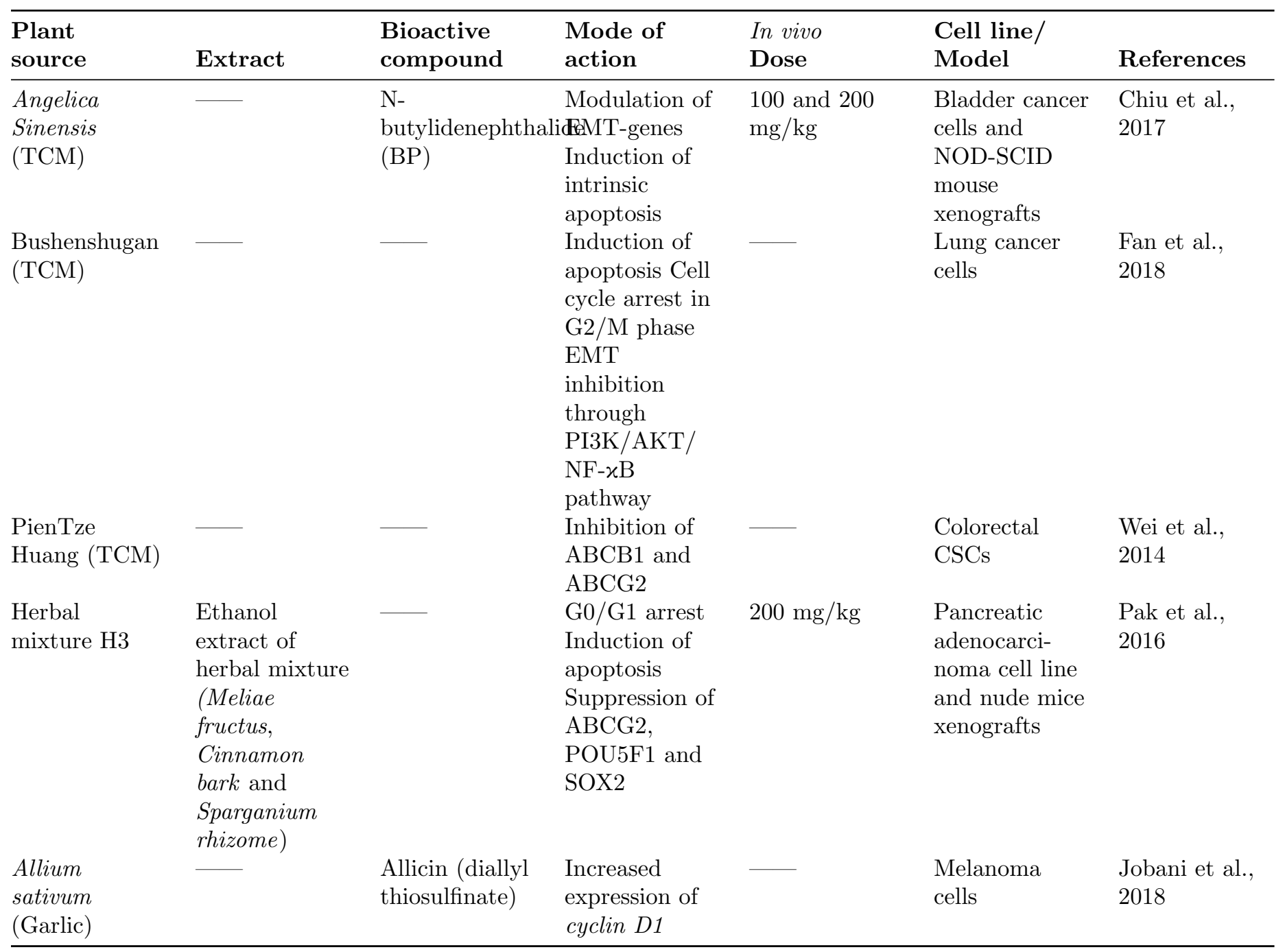

TCM: Traditional Chinese Medicine

Morusin, present in roots of Morus australis attenuated NF- $\chi \mathrm{B}$ activity in cervical CSCs, thus killing these tumor cells (L. Wang et al., 2013). Bushenshugan, a TCM inhibited EMT through PI3K/AKT/NF- $\chi \mathrm{B}$ pathway, induced apoptosis and caused cell cycle arrest in G2/M phase in lung cancer cells (Fan et al., 2018) . Glabridin, obtained from root extract of Glycyrrhiza glabraexhibited epigenetic regulation of miR148a/SMAD2 signaling and increased the survival of breast cancer mouse xenografts with $20 \mathrm{mg} / \mathrm{kg}$ dose of Glabridin (Jiang et al., 2016) .

$\mathrm{ABC}$ transporters are membrane proteins that act as efflux pumps, pumping out anti-cancer drugs and hence increase resistance to treatment(Yadav \& Desai, 2019) . ABC transporter genes like ABCG2 and ABCB5 are often found to be upregulated in cancers of pancreas, breast, lung, ovary and skin and can be potential target for therapy(Makena et al., 2020). PienTze Huang, a TCM consisting ofMoschus , Calculus Bovis , Snake Gall and Radix Notoginseng was shown to inhibit ABCB1 and ABCG2 in colorectal CSCs(Wei et al., 2014) .

4. Preclinical research on phytomedicines targeting Wnt, Notch and Hedgehog signaling in CSCs 
Wnt, Notch and Hedgehog signaling pathways are responsible for stem-like character of cancer cells and account for their self-renewal. Hence, compounds targeting these pathways could provide a way out in designing therapeutics as shown in Figure 4 (Hermawan \& Putri, 2018) .

\subsection{Phytomedicines targeting Wnt signaling pathway}

Various phytocompounds have proved to eliminate CSCs by modulating Wnt signaling pathway. It was demonstrated in a study that garlic derivative organosulfur compound diallyl trisulfide enhanced GSK3- $\beta$ expression and decreased $\beta$-catenin levels, signifying the suppression of $\mathrm{Wnt} / \beta$-catenin pathway in colorectal CSCs (Zhang et al., 2018). Koenimbin extracted from leaves of Murraya koenigii (L) Spreng induced $\beta$-catenin at Ser33/37/Thr41 and inhibited MCF7 breast CSCs(Kamalidehghan et al., 2015) . In another study, it has been shown that ginsenoside-Rb1, the main saponin present in rhizome of ginseng targets ovarian CSCs by inhibiting Wnt/ $\beta$-catenin signaling pathway and EMT. Compound K, a metabolite of ginsenosideRb1 was found to be effective in suppressing tumors in mouse xenografts ( $50 \mathrm{mg} / \mathrm{kg}$ dose of compound $\mathrm{K}$ ) (Deng et al., 2017) . Abrus agglutinin, a lectin extracted from seeds of Abrus precatorius was shown to induce apoptosis, inhibit EMT and interfere with Wnt/ $\beta$-catenin signaling in oral squamous carcinoma cells and suppressed the tumor with $50 \mu \mathrm{g} / \mathrm{kg}$ dose of purified Abrus agglutinin in xenografted nude mice(Sinha et al., 2017, 2019) . $60 \mathrm{mg} / \mathrm{kg}$ dose of Cruciferous sulforaphane inhibited nasopharyngeal CSCs in nude mice xenografts through DNA methyltransferase 1/Wnt inhibitory factor 1 axis(Chen et al., 2019) . Likewise, it caused suppression of miR-19 and Wnt/ $\beta$-catenin pathway and inhibited lung CSCs (Zhu et al., 2017) . Rhodiola crenulata root extract and chelerythrine chloride were shown to reduce $\beta$-catenin levels and thus suppress CSC characteristics (Bassa et al., 2016; Heng \& Cheah, 2020) . Sanguinarine, obtained from TCM celandine and water extract of Gynura divaricata also downregulated Wnt pathway (J. Yang et al., 2016; Yen et al., 2018) . Gomisin M2, an active component of a Chinese medicine Baizuan, exhibited apoptotic effect on breast CSCs and suppressed tumor with $10 \mu \mathrm{M}$ dose of Gomisin M2 in zebrafish xenografts(Y. Yang et al., 2019) . Evodiamine, a constituent ofEvodiae, exhibited anti-tumor activity against gastric and colon CSCs by dysregulation of Wnt pathway (Kim et al., 2019; Wen et al., 2015) .

\subsection{Phytomedicines targeting Notch signaling pathway}

Qingyihuaji formula, a TCM, composed of Herba Scutellariae Barbatae, Herba Hedyotdis, Herba seu Radix, Rhizoma Arisaematis Erubescentis, Gynostemmatis Pentaphylli andFructus Amomi Rotundus downregulated Notch pathway as reported in a study and $36 \mathrm{~g} / \mathrm{kg}$ dose of this compound increased the survival of pancreatic cancer mouse xenografts (Yanli et al., 2015). Similarly, 1.46, 2.92 and $5.84 \mathrm{~g} / \mathrm{mL}$ doses of Xiaotan Sanjie, a TCM showed suppression of Notch pathway and reduced tumor in gastric cancer xenograft models. Also, Pien Tze Huang exhibited modulation of Notch pathway in colorectal CSCs (Yan, 2014) . Suman et al., demonstrated that Psoralidin suppresses breast CSC by targeting NOTCH1-induced EMT (Suman et al., 2013) .

\subsection{Phytomedicines targeting Hedgehog signaling pathway}

Leaf extract of Withania somnifera was found to contain withaferin A, which targets hedgehog pathway by inhibiting GLI1-DNA complex (Yoneyama et al., 2015). Treatment of breast CSCs with curcumin was reported to downregulate Shh pathway (D. Wang et al., 2017). Similarly, sulforaphane showed promising results for elimination of pancreatic CSCs by suppression of Sonic hedgehog-GLI pathway (S.-H. Li et al., 2013) . BRM270, significantly suppressed Shh/Gli1 signaling pathway, contributing to EMT gene downregulation, and thus prevented metastasis of CD44+ pancreatic ductal adenocarcinoma cells (PDAC) cells. In vivo study established that tumor growth derived from CD44+ PDAC was suppressed by $5 \mathrm{mg} / \mathrm{kg}$ dose of BRM270 (Huynh et al., 2019) . Baicalein, an active compound in the formulation of Qingyihuaji, was evidently described to repress the self-renewal of pancreatic CSCs by inhibiting the signaling pathway of Sonic Hedgehog (Song et al., 2018) . Honokiol, obtained from Magnolia plant also inhibited Shh, thus suppressed the growth of pancreatic cancer with $150 \mathrm{mg} / \mathrm{kg}$ dose in mouse xenograft model(Averett et al., 2016) .

A study established that, MSC500, a Korean herbal preparation consisting primarily of 8 herbs including 
Phellinus linteus, Gastrodiaelata, and Mulberry leaf modulated all three signaling pathways (Notch, Wnt, and Hedgehog) in glioblastoma cells (Yao et al., 2014). It has been observed that treatment of CSCs with phytomedicines improves their sensitization to conventional chemotherapy drugs. Ovatodiolide was shown to augment the chemotherapeutic effect of temozolomide for glioblastoma cells (Su et al., 2019) . Furthermore, it enhanced the cisplatin treatment for nasopharyngeal (S.-C. Liu et al., 2019) and oral CSCs (Lin et al., 2018). Similarly, sulforaphane, found in cruciferous vegetables enhanced cisplatin treatment for nasopharyngeal carcinoma (Chen et al., 2019). Curcumin improved the sensitivity of paclitaxel, cisplatin, doxorubicin, and mitomycin C for breast CSCs (Zhou et al., 2015) . Studies have shown that ginsenoside-Rb1 improved cisplatin and

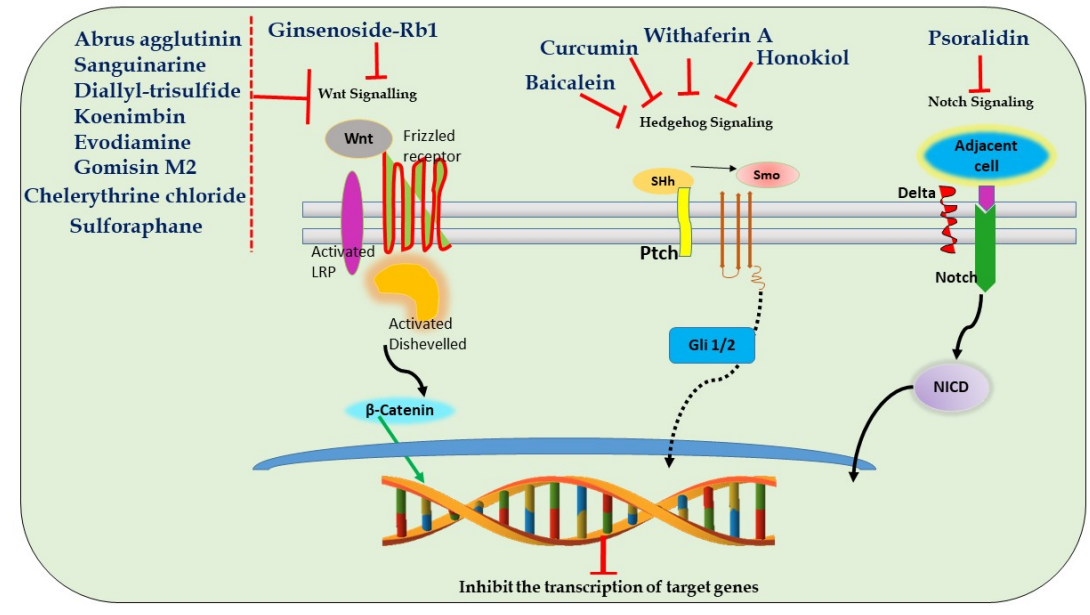

Figure 4. Phytocompounds targeting Wnt, Notch and Hedgehog signaling in CSCs. Abrus agglutinin, Sanguinarine, Diallyl-trisulfide, Koenimbin, Evodiamine, Gomisin M2, Chelerythrine chloride, Sulforaphane and Ginsenoside-Rb1 inhibit Wnt signaling pathway. Baicalein, Curcumin, Withaferin A and Honokiol target Hedgehog signaling pathway. Psoralidin targets Notch signaling pathway.

Table 3. Phytocompounds targeting Wnt, Notch and Hedgehog signaling in CSCs.

\begin{tabular}{|c|c|c|c|c|c|c|}
\hline $\begin{array}{l}\text { Plant } \\
\text { source }\end{array}$ & Extract & $\begin{array}{l}\text { Bioactive } \\
\text { compound }\end{array}$ & $\begin{array}{l}\text { Mode of } \\
\text { action }\end{array}$ & $\begin{array}{l}\text { In vivo } \\
\text { Dose }\end{array}$ & $\begin{array}{l}\text { Cell } \\
\text { line/Model }\end{array}$ & Reference \\
\hline $\begin{array}{l}\text { Abrus } \\
\text { precatorius }\end{array}$ & Seed extract & $\begin{array}{l}\text { Abrus } \\
\text { agglutinin } \\
\text { (AGG) }\end{array}$ & $\begin{array}{l}\text { p73 suppressed } \\
\text { Snail } \\
\text { expression, } \\
\text { leading to } \\
\text { EMT } \\
\text { inhibition } \\
\text { Induction of } \\
\text { intrinsic and } \\
\text { extrinsic } \\
\text { apoptosis } \\
\text { Inactivation of } \\
\text { Wnt/ } \beta \text {-catenin } \\
\text { signaling } \\
\text { pathway }\end{array}$ & $50 \mu \mathrm{g} / \mathrm{kg}$ & $\begin{array}{l}\text { Oral squamous } \\
\text { cell carcinoma } \\
\text { cells and } \\
\text { xenografted } \\
\text { nude mice }\end{array}$ & $\begin{array}{l}\text { Sinha et al., } \\
2017,2019\end{array}$ \\
\hline
\end{tabular}




\begin{tabular}{|c|c|c|c|c|c|c|}
\hline $\begin{array}{l}\text { Plant } \\
\text { source }\end{array}$ & Extract & $\begin{array}{l}\text { Bioactive } \\
\text { compound }\end{array}$ & $\begin{array}{l}\text { Mode of } \\
\text { action }\end{array}$ & $\begin{array}{l}\text { In vivo } \\
\text { Dose }\end{array}$ & $\begin{array}{l}\text { Cell } \\
\text { line/Model }\end{array}$ & Reference \\
\hline $\begin{array}{l}\text { Celandine } \\
(\mathrm{TCM})\end{array}$ & $\overline{-}$ & Sanguinarine & $\begin{array}{l}\text { Downregulation } \\
\text { of } \\
\text { Wnt/ } \beta \text {-catenin } \\
\text { signaling } \\
\text { pathway }\end{array}$ & $0.5 \mathrm{mg} / 20 \mathrm{~g}$ & $\begin{array}{l}\text { Lung CSCs } \\
\text { and } \\
\text { xenografted } \\
\text { nude mice }\end{array}$ & $\begin{array}{l}\text { Yang et al., } \\
2016\end{array}$ \\
\hline $\begin{array}{l}\text { Gynura } \\
\text { divaricata } \\
\text { subsp. } \\
\text { formosana }\end{array}$ & $\begin{array}{l}\text { Aqueous } \\
\text { extract of } \\
\text { aerial part }\end{array}$ & - & $\begin{array}{l}\text { Downregulation } \\
\text { of } \\
\text { Wnt/ } \beta \text {-catenin } \\
\text { signaling } \\
\text { pathway }\end{array}$ & $300 \mathrm{mg} / \mathrm{kg}$ & $\begin{array}{l}\text { Hepatocellular } \\
\text { CSCs and } \\
\text { xenograft mice } \\
\text { model }\end{array}$ & $\begin{array}{l}\text { Yen et al., } \\
2018\end{array}$ \\
\hline $\begin{array}{l}\text { Panax } \\
\text { quinquefolius }\end{array}$ & - & $\begin{array}{l}\text { Ginsenoside- } \\
\text { Rb1 }\end{array}$ & $\begin{array}{l}\text { Inhibition of } \\
\text { Wnt/ } \beta \text {-catenin } \\
\text { signaling } \\
\text { Inhibition of } \\
\text { EMT }\end{array}$ & $50 \mathrm{mg} / \mathrm{kg}$ & $\begin{array}{l}\text { Ovarian CSCs } \\
\text { and mouse } \\
\text { xenograft } \\
\text { models }\end{array}$ & $\begin{array}{l}\text { Deng et al., } \\
2017\end{array}$ \\
\hline $\begin{array}{l}\text { Allium } \\
\text { sativum } \\
\text { (Garlic) }\end{array}$ & - & $\begin{array}{l}\text { Diallyl- } \\
\text { trisulfide }\end{array}$ & $\begin{array}{l}\text { Induction of } \\
\text { apoptosis } \\
\text { Modulation of } \\
\text { Wnt/ } \beta \text {-catenin } \\
\text { signaling } \\
\text { pathway }\end{array}$ & - & $\begin{array}{l}\text { Colorectal } \\
\text { CSCs }\end{array}$ & $\begin{array}{l}\text { Zhang et al., } \\
2018\end{array}$ \\
\hline \multirow[t]{2}{*}{$\begin{array}{l}\text { Murraya } \\
\text { koenigii }(L) \\
\text { Spreng }\end{array}$} & Leaf extract & Koenimbin & $\begin{array}{l}\text { Induction of } \\
\text { apoptosis by } \\
\text { intrinsic } \\
\text { pathway } \\
\text { Downregula- } \\
\text { tion of } \\
\text { Wnt/ } \beta \text {-catenin } \\
\text { self-renewal } \\
\text { pathway }\end{array}$ & $\longrightarrow$ & Breast CSCs & $\begin{array}{l}\text { Kamalidehghan } \\
\text { et al., } 2015\end{array}$ \\
\hline & & & $\begin{array}{l}\text { Induction of } \\
\text { apoptosis via } \\
\text { intrinsic } \\
\text { pathway } \\
\text { G0/G1 phase } \\
\text { arrest }\end{array}$ & & Prostate CSCs & $\begin{array}{l}\text { Kamalidehghan } \\
\text { et al., } 2018\end{array}$ \\
\hline $\begin{array}{l}\text { Rhodiola } \\
\text { crenulata }\end{array}$ & Root extract & - & $\begin{array}{l}\text { Decreased } \\
\beta \text {-catenin } \\
\text { expression }\end{array}$ & $20 \mathrm{mg} / \mathrm{kg}$ & $\begin{array}{l}\text { MCF-7 } \\
\text { Estrogen } \\
\text { receptor } \\
\text { positive } \\
(\text { ER+) breast } \\
\text { cancer cells } \\
\text { and mouse } \\
\text { xenograft } \\
\text { model }\end{array}$ & $\begin{array}{l}\text { Bassa et al., } \\
2016\end{array}$ \\
\hline $\begin{array}{l}\text { Chelidonium } \\
\text { ma- } \\
\text { jus/Macleaya } \\
\text { cordata }\end{array}$ & $\longrightarrow$ & $\begin{array}{l}\text { Chelerythrine } \\
\text { chloride }\end{array}$ & $\begin{array}{l}\text { Downregulation } \\
\text { of } \beta \text {-catenin }\end{array}$ & $\longrightarrow$ & $\begin{array}{l}\text { Non-small cell } \\
\text { lung } \\
\text { carcinoma } \\
\text { stem-like cells }\end{array}$ & $\begin{array}{l}\text { Heng \& } \\
\text { Cheah, } 2020\end{array}$ \\
\hline
\end{tabular}




\begin{tabular}{|c|c|c|c|c|c|c|}
\hline $\begin{array}{l}\text { Plant } \\
\text { source }\end{array}$ & Extract & $\begin{array}{l}\text { Bioactive } \\
\text { compound }\end{array}$ & $\begin{array}{l}\text { Mode of } \\
\text { action }\end{array}$ & $\begin{array}{l}\text { In vivo } \\
\text { Dose }\end{array}$ & $\begin{array}{l}\text { Cell } \\
\text { line/Model }\end{array}$ & Reference \\
\hline $\begin{array}{l}\text { Evodiae } \\
\text { rutaecarpa }\end{array}$ & - & Evodiamine & $\begin{array}{l}\text { Inhibition of } \\
\text { Wnt Signaling }\end{array}$ & 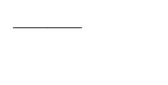 & Gastric CSCs & $\begin{array}{l}\text { Wen et al., } \\
2015\end{array}$ \\
\hline $\begin{array}{l}\text { Evodiae } \\
\text { fructus }\end{array}$ & - & Evodiamine & $\begin{array}{l}\text { Induction of } \\
\text { apoptosis } \\
\text { Suppression of } \\
\text { Notch and } \\
\text { Wnt Signaling }\end{array}$ & - & Colon CSCs & $\begin{array}{l}\text { Kim et al., } \\
2019\end{array}$ \\
\hline $\begin{array}{l}\text { Baizuan } \\
\text { (TCM) }\end{array}$ & - & Gomisin M2 & $\begin{array}{l}\text { Downregulation } \\
\text { of } \\
\text { Wnt/ } \beta \text {-catenin } \\
\text { signaling } \\
\text { pathway } \\
\text { Induction of } \\
\text { apoptosis }\end{array}$ & $10 \mu \mathrm{M}$ & $\begin{array}{l}\text { Breast CSCs } \\
\text { and zebrafish } \\
\text { xenograft }\end{array}$ & $\begin{array}{l}\text { Yang et al., } \\
2019\end{array}$ \\
\hline \multirow[t]{3}{*}{$\begin{array}{l}\text { Cruciferous } \\
\text { vegetables }\end{array}$} & - & $\begin{array}{l}\text { Sulforaphane } \\
\text { (SFN) }\end{array}$ & $\begin{array}{l}\text { Downregulation } \\
\text { of DNA } \\
\text { methyltrans- } \\
\text { ferase1 } \\
\text { (DNMT1) } \\
\text { Restoring the } \\
\text { expression of } \\
\text { Wnt inhibitory } \\
\text { factor } 1 \\
\text { (WIF1) }\end{array}$ & $60 \mathrm{mg} / \mathrm{kg}$ & $\begin{array}{l}\text { Nasopharyngeal } \\
\text { carcinoma } \\
\text { cells and nude } \\
\text { mice xenograft }\end{array}$ & $\begin{array}{l}\text { Chen et al., } \\
2019\end{array}$ \\
\hline & & & $\begin{array}{l}\text { Suppression of } \\
\text { miR-19 and } \\
\text { Wnt/ } / \text {-catenin } \\
\text { pathway }\end{array}$ & $\longrightarrow$ & Lung CSCs & $\begin{array}{l}\text { Zhu et al., } \\
2017\end{array}$ \\
\hline & & & $\begin{array}{l}\text { Modulation of } \\
\text { Sonic } \\
\text { hedgehog-GLI } \\
\text { pathway } \\
\text { Inhibition of } \\
\text { pluripotency } \\
\text { markers, } \\
\text { angiogenesis } \\
\text { markers and } \\
\text { EMT markers }\end{array}$ & - & $\begin{array}{l}\text { Pancreatic } \\
\text { CSCs }\end{array}$ & Li et al., 2013 \\
\hline $\begin{array}{l}\text { Curcuma longa } \\
\text { (Turmeric) }\end{array}$ & - & Curcumin & $\begin{array}{l}\text { Suppression of } \\
\text { Sonic } \\
\text { Hedgehog } \\
\text { pathway } \\
\text { Induction of } \\
\text { apoptosis } \\
\text { Decreased } \\
\text { expression of } \\
\text { CSC markers }\end{array}$ & - & Bladder CSCs & $\begin{array}{l}\text { Wang et al., } \\
2017\end{array}$ \\
\hline
\end{tabular}




\begin{tabular}{|c|c|c|c|c|c|c|}
\hline $\begin{array}{l}\text { Plant } \\
\text { source }\end{array}$ & Extract & $\begin{array}{l}\text { Bioactive } \\
\text { compound }\end{array}$ & $\begin{array}{l}\text { Mode of } \\
\text { action }\end{array}$ & $\begin{array}{l}\text { In vivo } \\
\text { Dose }\end{array}$ & $\begin{array}{l}\text { Cell } \\
\text { line/Model }\end{array}$ & Reference \\
\hline $\begin{array}{l}\text { Withania } \\
\text { somnifera } \\
\text { (Ashwagandha) }\end{array}$ & Leaf extract & Withaferin A & $\begin{array}{l}\text { Hh signal } \\
\text { inhibition }\end{array}$ & 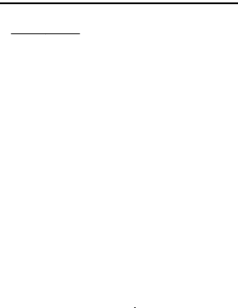 & $\begin{array}{l}\text { Human } \\
\text { pancreatic } \\
\text { (PANC-1), } \\
\text { prostate } \\
\text { (DU145) and } \\
\text { breast (MCF7) } \\
\text { cancer cells }\end{array}$ & $\begin{array}{l}\text { Yoneyama et } \\
\text { al., } 2015\end{array}$ \\
\hline Magnolia & - & $\begin{array}{l}\text { Honokiol } \\
\text { (HNK) }\end{array}$ & $\begin{array}{l}\text { Decreased } \\
\text { expression of } \\
\text { sonic hedgehog } \\
\text { and CXCR4 } \\
\text { Inhibition of } \\
\text { NF- } x \mathrm{~B}\end{array}$ & $150 \mathrm{mg} / \mathrm{kg}$ & $\begin{array}{l}\text { Pancreatic } \\
\text { cancer cells } \\
\text { and nude mice } \\
\text { xenograft }\end{array}$ & $\begin{array}{l}\text { Averett et al., } \\
2016\end{array}$ \\
\hline BRM270 & $\begin{array}{l}\text { Alcohol } \\
\text { extract }\end{array}$ & - & $\begin{array}{l}\text { Suppression of } \\
\text { Sonic } \\
\text { Hedgehog } \\
\text { pathway } \\
\text { Induction of } \\
\text { apoptosis }\end{array}$ & $5 \mathrm{mg} / \mathrm{kg}$ & $\begin{array}{l}\text { Pancreatic } \\
\text { ductal adeno- } \\
\text { carcinoma } \\
\text { stem cells and } \\
\text { nude mice } \\
\text { xenograft }\end{array}$ & $\begin{array}{l}\text { Huynh et al., } \\
2019\end{array}$ \\
\hline $\begin{array}{l}\text { Qingyihuaji } \\
\text { (TCM) }\end{array}$ & - & Baicalein & $\begin{array}{l}\text { Modulation of } \\
\text { Sonic } \\
\text { Hedgehog } \\
\text { pathway }\end{array}$ & $\begin{array}{l}20 \text { or } 60 \\
\mathrm{mg} / \mathrm{kg}\end{array}$ & $\begin{array}{l}\text { Pancreatic } \\
\text { CSCs and } \\
\text { mice xenograft }\end{array}$ & $\begin{array}{l}\text { Song et al., } \\
2018\end{array}$ \\
\hline $\begin{array}{l}\text { Qingyihuaji } \\
\text { (TCM) }\end{array}$ & Water extract & - & $\begin{array}{l}\text { Downregulation } \\
\text { of Notch- } 4 \text { and } \\
\text { Jagged-1 in } \\
\text { Notch } \\
\text { signaling } \\
\text { pathway }\end{array}$ & $36 \mathrm{~g} / \mathrm{kg}$ & $\begin{array}{l}\text { Pancreatic } \\
\text { cancer nude } \\
\text { mice xenograft }\end{array}$ & $\begin{array}{l}\text { Yanli et al., } \\
2015\end{array}$ \\
\hline $\begin{array}{l}\text { Xiaotansanjie } \\
(\mathrm{TCM})\end{array}$ & $\longrightarrow$ & & $\begin{array}{l}\text { Inhibition of } \\
\text { Notch-1 }\end{array}$ & $\begin{array}{l}1.46,2.92 \text { and } \\
5.84 \mathrm{~g} / \mathrm{mL}\end{array}$ & $\begin{array}{l}\text { Gastric CSCs } \\
\text { and mouse } \\
\text { xenografts }\end{array}$ & Yan, 2014 \\
\hline $\begin{array}{l}\text { Psoralea } \\
\text { corylifolia }\end{array}$ & - & Psoralidin & $\begin{array}{l}\text { Inhibition of } \\
\text { Notch-1 } \\
\text { signaling } \\
\text { Inhibition of } \\
\text { EMT }\end{array}$ & - & Breast CSCs & $\begin{array}{l}\text { Suman et al., } \\
2013\end{array}$ \\
\hline $\begin{array}{l}\text { PienTze } \\
\text { Huang (TCM) }\end{array}$ & 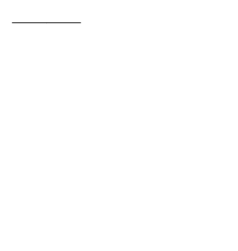 & - & $\begin{array}{l}\text { Induction of } \\
\text { apoptosis } \\
\text { Suppression of } \\
\text { Notch-1 } \\
\text { signaling } \\
\text { pathway }\end{array}$ & 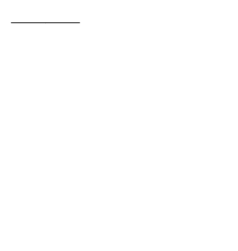 & $\begin{array}{l}\text { Colorectal } \\
\text { CSCs }\end{array}$ & Qi et al., 2016 \\
\hline
\end{tabular}




\begin{tabular}{|c|c|c|c|c|c|c|}
\hline $\begin{array}{l}\text { Plant } \\
\text { source }\end{array}$ & Extract & $\begin{array}{l}\text { Bioactive } \\
\text { compound }\end{array}$ & $\begin{array}{l}\text { Mode of } \\
\text { action }\end{array}$ & $\begin{array}{l}\text { In vivo } \\
\text { Dose }\end{array}$ & $\begin{array}{l}\text { Cell } \\
\text { line/Model }\end{array}$ & Reference \\
\hline MSC500 & 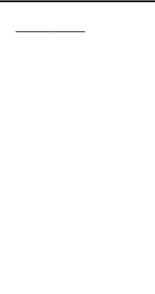 & 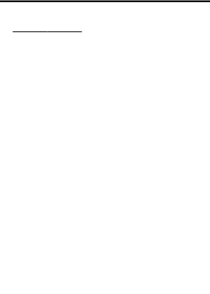 & $\begin{array}{l}\text { Suppression of } \\
\text { ALDH, } \\
\text { ABCB5, } \\
\text { Oct- } 4 \text {, Sox-2, } \\
\beta \text {-catenin, } \\
\text { Gli-1, and } \\
\text { Notch-1 }\end{array}$ & 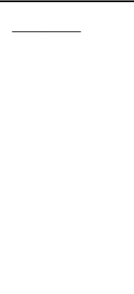 & $\begin{array}{l}\text { Glioblastoma } \\
\text { stem cells }\end{array}$ & $\begin{array}{l}\text { Yao et al., } \\
2014\end{array}$ \\
\hline
\end{tabular}

\section{TCM: Traditional Chinese Medicine}

paclitaxel treatment for ovarian CSCs (Deng et al., 2017) . Carnosol sensitized glioblastoma CSCs to temozolomide anti-proliferative effects (Giacomelli et al., 2017). Phytomedicines not only help in reducing CSC resistance to treatment; but also show positive results when given as a combination therapy. A study by Yen et al. depicted that combinations of Gynura divaricata extract and cisplatin or doxorubicin or 5-FU show high level of synergism for treating hepatocellular carcinoma (Yen et al., 2018) .

\section{Clinical research}

Various clinical trials of anti-CSC phytomedicines have been carried out to evaluate their safety and efficacy. In patients with acute myeloid leukemia (AML), Compound Zhebei Granule combined with chemotherapy was reported to reduce the percentages of CD34+, CD123+ and CD33+, CD123+ leukemia stem cells(J. Wang et al., 2016) . Further, Table 4. summarizes the clinical status of phytomedicines targeting CSCs.

Table 4. Clinical status of phytomedicines targeting CSCs.

\begin{tabular}{|c|c|c|c|c|}
\hline Clinical Trial No. & $\begin{array}{l}\text { Sponsors and } \\
\text { Collaborators }\end{array}$ & Title of Study & Clinical Status & $\begin{array}{l}\text { Year of study } \\
\text { (Start } \\
\text { Date-Completion } \\
\text { Date) }\end{array}$ \\
\hline $\begin{array}{l}\text { Cruciferous } \\
\text { veg- }\end{array}$ & $\begin{array}{l}\text { Cruciferous } \\
\text { veg- }\end{array}$ & $\begin{array}{l}\text { Cruciferous } \\
\text { veg- }\end{array}$ & $\begin{array}{l}\text { Cruciferous } \\
\text { veg- }\end{array}$ & $\begin{array}{l}\text { Cruciferous } \\
\text { veg- }\end{array}$ \\
\hline \multicolumn{5}{|c|}{ etable/Sulforaphaneetable/Sulforaphaneetable/Sulforaphaneetable/Sulforaphaneetable/Sulforaphan } \\
\hline NCT00982319 & $\begin{array}{l}\text { Sidney Kimmel } \\
\text { Comprehensive } \\
\text { Cancer Center at } \\
\text { Johns Hopkins }\end{array}$ & $\begin{array}{l}\text { Study to Evaluate } \\
\text { the Effect } \\
\text { of Sulforaphane in } \\
\text { Broccoli Sprout } \\
\text { Extract on Breast } \\
\text { Tissue }\end{array}$ & Phase 2 & 2009-2013 \\
\hline NCT03665922 & $\begin{array}{l}\text { University of } \\
\text { Pittsburgh }\end{array}$ & $\begin{array}{l}\text { Biomarkers of Sul- } \\
\text { foraphane/Broccoli } \\
\text { Sprout Extract in } \\
\text { Prostate Cancer }\end{array}$ & $\begin{array}{l}\text { Recruiting (Phase } \\
\text { not applicable) }\end{array}$ & 2019-2024 \\
\hline Curcumin & Curcumin & Curcumin & Curcumin & Curcumin \\
\hline
\end{tabular}




\begin{tabular}{|c|c|c|c|c|}
\hline Clinical Trial No. & $\begin{array}{l}\text { Sponsors and } \\
\text { Collaborators }\end{array}$ & Title of Study & Clinical Status & $\begin{array}{l}\text { Year of study } \\
\text { (Start } \\
\text { Date-Completion } \\
\text { Date) }\end{array}$ \\
\hline NCT01740323 & $\begin{array}{l}\text { Andrew H Miller } \\
\text { and National } \\
\text { Cancer Institute } \\
\text { (NCI) }\end{array}$ & $\begin{array}{l}\text { Phase II Study } \\
\text { of Curcumin vs } \\
\text { Placebo for } \\
\text { Chemotherapy- } \\
\text { Treated Breast } \\
\text { Cancer Patients } \\
\text { Undergoing } \\
\text { Radiotherapy }\end{array}$ & Phase 2 & $2015-2018$ \\
\hline NCT03980509 & $\begin{array}{l}\text { Medical } \\
\text { University of } \\
\text { South Carolina }\end{array}$ & $\begin{array}{l}\text { A "Window } \\
\text { Trial" } \\
\text { on Curcumin for } \\
\text { Invasive Breast } \\
\text { Cancer Pri- } \\
\text { mary Tumors }\end{array}$ & Phase 1 & $2020-2021$ \\
\hline NCT03072992 & $\begin{array}{l}\text { National Center } \\
\text { of Oncology, } \\
\text { Armenia and } \\
\text { BRIU GmbH }\end{array}$ & $\begin{array}{l}\text { "Curcumin" in } \\
\text { Combination with } \\
\text { Chemotherapy in } \\
\text { Advanced Breast } \\
\text { Cancer }\end{array}$ & Phase 2 & 2017-2019 \\
\hline $\begin{array}{l}\text { Cruciferous } \\
\text { vegetable/ } \\
\text { Phenethyl } \\
\text { isothio- } \\
\text { cyanate (PEITC) }\end{array}$ & $\begin{array}{l}\text { Cruciferous } \\
\text { vegetable/ } \\
\text { Phenethyl } \\
\text { isothio- } \\
\text { cyanate (PEITC) }\end{array}$ & $\begin{array}{l}\text { Cruciferous } \\
\text { vegetable/ } \\
\text { Phenethyl } \\
\text { isothio- } \\
\text { cyanate (PEITC) }\end{array}$ & $\begin{array}{l}\text { Cruciferous } \\
\text { vegetable/ } \\
\text { Phenethyl } \\
\text { isothio- } \\
\text { cyanate (PEITC) }\end{array}$ & $\begin{array}{l}\text { Cruciferous } \\
\text { vegetable/ } \\
\text { Phenethyl } \\
\text { isothio- } \\
\text { cyanate (PEITC) }\end{array}$ \\
\hline NCT01790204 & $\begin{array}{l}\text { Georgetown } \\
\text { University }\end{array}$ & $\begin{array}{l}\text { A Study of the } \\
\text { Effects } \\
\text { of PEITC on Oral } \\
\text { Cells with Mutant } \\
\text { p53 }\end{array}$ & Phase 2 & $2012-2014$ \\
\hline NCT00691132 & $\begin{array}{l}\text { University of } \\
\text { Minnesota and } \\
\text { National Cancer } \\
\text { Institute (NCI) }\end{array}$ & $\begin{array}{l}\text { Phenethyl } \\
\text { Isothiocyanate in } \\
\text { Preventing } \\
\text { Lung Cancer in } \\
\text { Smokers }\end{array}$ & Phase 2 & 2009-2013 \\
\hline Garlic & Garlic & Garlic & Garlic & Garlic \\
\hline NCT00079170 & $\begin{array}{l}\text { National Cancer } \\
\text { Institute (NCI) }\end{array}$ & $\begin{array}{l}\text { Docetaxel } \\
\text { Plus Garlic in } \\
\text { Treating Patients } \\
\text { with Locally } \\
\text { Advanced or } \\
\text { Metastatic } \\
\text { Breast Cancer }\end{array}$ & $\begin{array}{l}\text { Pilot study } \\
\text { (Phase not } \\
\text { applicable) }\end{array}$ & $2004-2007$ \\
\hline Berberine & Berberine & Berberine & Berberine & Berberine \\
\hline
\end{tabular}




\begin{tabular}{|c|c|c|c|c|}
\hline Clinical Trial No. & $\begin{array}{l}\text { Sponsors and } \\
\text { Collaborators }\end{array}$ & Title of Study & Clinical Status & $\begin{array}{l}\text { Year of study } \\
\text { (Start } \\
\text { Date-Completion } \\
\text { Date) }\end{array}$ \\
\hline NCT02226185 & $\begin{array}{l}\text { Shanghai Jiao } \\
\text { Tong University } \\
\text { School of } \\
\text { Medicine }\end{array}$ & $\begin{array}{l}\text { Study of Berber- } \\
\text { ine Hydrochloride } \\
\text { in Prevention of } \\
\text { Colorectal } \\
\text { Adenomas } \\
\text { Recurrence }\end{array}$ & Phase 3 & $2014-2018$ \\
\hline Licorice & Licorice & Licorice & Licorice & Licorice \\
\hline NCT00176631 & $\begin{array}{l}\text { Rutgers, The } \\
\text { State University } \\
\text { of New Jersey and } \\
\text { National Cancer } \\
\text { Institute (NCI) }\end{array}$ & $\begin{array}{l}\text { Licorice Root } \\
\text { Extract and } \\
\text { Docetaxel in } \\
\text { Treating Patients } \\
\text { with Metastatic } \\
\text { Prostate Can- } \\
\text { cer That Did Not } \\
\text { Respond to } \\
\text { Hormone Therapy }\end{array}$ & Phase 2 & $2007-2008$ \\
\hline $\begin{array}{l}\mathrm{N}- \\
\text { butylidenephthalide }\end{array}$ & $\begin{array}{l}\text { N- } \\
\text { butylidenephthal }\end{array}$ & $\begin{array}{l}\text { N- } \\
\text { butylidenephtha }\end{array}$ & $\begin{array}{l}\text { N- } \\
\text { butylidenephth }\end{array}$ & $\begin{array}{l}\text { N- } \\
\text { butylidenephthali }\end{array}$ \\
\hline NCT03234595 & $\begin{array}{l}\text { Everfront Biotech } \\
\text { Co., Ltd. }\end{array}$ & $\begin{array}{l}\text { A Phase I/IIa } \\
\text { Study of } \\
\text { Cerebraca Wafer } \\
\text { Plus Adjuvant } \\
\text { Temozolomide } \\
\text { (TMZ) in } \\
\text { Patients with } \\
\text { Recurrent } \\
\text { High-Grade } \\
\text { Glioma }\end{array}$ & Phase 2 & $2017-2021$ \\
\hline Ginsenoside & Ginsenoside & Ginsenoside & Ginsenoside & Ginsenoside \\
\hline NCT02714608 & $\begin{array}{l}\text { Tasly } \\
\text { Pharmaceuticals, } \\
\text { Inc. }\end{array}$ & $\begin{array}{l}\text { A Study } \\
\text { of Ginsenoside H } \\
\text { Dripping Pills for } \\
\text { Advanced } \\
\text { Non-Small Cell } \\
\text { Lung Can- } \\
\text { cer (NSCLC) }\end{array}$ & Phase 2 & $2016-2018$ \\
\hline $\begin{array}{l}\text { Ashwagandha } \\
\text { NCT00689195 }\end{array}$ & $\begin{array}{l}\text { Ashwagandha } \\
\text { Tata Memorial } \\
\text { Hospital and } \\
\text { Pharmanza } \\
\text { Herbals Pvt } \\
\text { Limited (PHPL) }\end{array}$ & $\begin{array}{l}\text { Ashwagandha } \\
\text { Pilot Study of } \\
\text { Curcumin } \\
\text { Formulation } \\
\text { and Ashwa- } \\
\text { gandha Extract in } \\
\text { Advanced } \\
\text { Osteosarcoma } \\
\text { (OSCAT) }\end{array}$ & $\begin{array}{l}\text { Ashwagandha } \\
\text { Phase } 2\end{array}$ & $\begin{array}{l}\text { Ashwagandha } \\
2008-2013\end{array}$ \\
\hline
\end{tabular}




\section{Conclusion and Future perspectives}

Since cancer is a fatal disease affecting millions of people over worldwide, there is a great necessity of different treatment options to overcome the drug resistance or recurrence conditions in cancer patients. Medicinal plants and their bioactive compounds have been a very good and easily accessible source for the development of novel therapeutics for different diseases. Even though hundreds of plants have been tested for cancer, a very few of them have been studied in vitro and in vivo, and only few of them are under clinical trials. In view of that, information on recent preclinical and clinical studies of medicinal plants, their bioactive compounds and herbal edibles used against CSCs, is compiled in the present study. Phytomedicines targeting Hedgehog, Wnt and Notch signaling pathways as well as those targeting CSC resistance mechanisms have been listed. Treatment of cancer cells with phytocompounds has proven to reduce the resistance to chemotherapy. Further investigations are necessary to find the combinatorial effects of chemotherapeutic agents and plant extracts/compounds. Also, whether combination of two different isolated phytocompounds shows synergism, antagonism or additive effect needs to be explored.

In most of the studies, the main phytoconstituent is purified and then tested. However, in case the whole plant or the extract of a particular plant part is used, the bioactive compound present in it needs to be characterized and its mode of action against CSC should be determined. This is because, there might be presence of more than one bioactive compound, each showing different mechanism; which needs to be investigated. High throughput screening can prove to be useful in selecting phytocompounds for targeting CSCs of a particular type of cancer.

Throughout research is required to ascertain preclinical and clinical safety as well as efficacy of the plantderived bioactive compounds. Studies based on pharmacodynamic and pharmacokinetic properties of the phytochemicals will provide a better understanding. Poor solubility, decreased stability and shorter circulation time in the blood are the common problems faced in drug treatment and hence nanoparticles-based delivery, liposomes and hydrogel formulations for these phytocompounds can be designed. $\mathrm{pH}$, temperature or tumor microenvironment responsive intelligent nanodrug carriers, specifically targeting CSCs, might be used and needs further exploration.

\section{Declaration of Competing Interest}

Authors declare no competing interest with respect to the work performed in the manuscript.

\section{Funding}

DKB acknowledges the funding support from Science and Engineering Research Board (SERB), Department of Science and Technology, Govt. of India for the "Start-up Research Grant - 2019" (SRG/2019/001995).

\section{Acknowledgement}

PKG is thankful to Department of Life Sciences, School of Basic Sciences and Research, Sharda University, Greater Noida for providing infrastructure and facility for research.

\section{Author Contributions}

Mrs. Mrunmayee Saraff contributed in the collection of the literature, writing and editing the manuscript drafts. Ms. Rekha Gahtori contributed in drawing the figures. Dr. Sugapriya Dhanasekaran, Dr. Sanjay Kumar, Dr. Soumya Pandit, Dr. Dillip Kumar Bishi and Mr. Surya Kant Tripathi contributed in editing the draft and provided the critical inputs in the review discussion. Dr. Piyush Kumar Gupta conceptualized, planned and finalized the manuscript.

\section{ORCID}

Dr. Piyush Kumar Gupta -https://orcid.org/0000-0002-3346-910X

\section{References}


Antony, J., Thiery, J. P., \& Huang, R. Y.-J. (2019). Epithelial-to-mesenchymal transition: Lessons from development, insights into cancer and the potential of EMT-subtype based therapeutic intervention. Physical Biology , 16 (4), 041004. https://doi.org/10.1088/1478-3975/ab157a

Averett, C., Bhardwaj, A., Arora, S., Srivastava, S. K., Khan, M. A., Ahmad, A., Singh, S., Carter, J. E., Khushman, M., \& Singh, A. P. (2016). Honokiol suppresses pancreatic tumor growth, metastasis and desmoplasia by interfering with tumor-stromal crosstalk.Carcinogenesis , 37 (11), 1052-1061. https://doi.org/10.1093/carcin/bgw096

Barbato, L., Bocchetti, M., Di Biase, A., \& Regad, T. (2019). Cancer Stem Cells and Targeting Strategies. Cells , 8 (8), 926. https://doi.org/10.3390/cells8080926

Bassa, L. M., Jacobs, C., Gregory, K., Henchey, E., Ser-Dolansky, J., \& Schneider, S. S. (2016). Rhodiola crenulata induces an early estrogenic response and reduces proliferation and tumorsphere formation over time in MCF7 breast cancer cells. Phytomedicine , 23 (1), 87-94. https://doi.org/10.1016/j.phymed.2015.11.014

Batlle, E., \& Clevers, H. (2017). Cancer stem cells revisited.Nature Medicine , 23 (10), 1124-1134. https://doi.org/10.1038/nm.4409

Bhummaphan, N., Petpiroon, N., Prakhongcheep, O., Sritularak, B., \& Chanvorachote, P. (2019). Lusianthridin targeting of lung cancer stem cells via Src-STAT3 suppression. Phytomedicine , 62 , 152932. https://doi.org/10.1016/j.phymed.2019.152932

Bonam, S. R., Wu, Y. S., Tunki, L., Chellian, R., Halmuthur, M. S. K., Muller, S., \& Pandy, V. (2018). What Has Come out from Phytomedicines and Herbal Edibles for the Treatment of Cancer? ChemMedChem ,13 (18), 1854-1872. https://doi.org/10.1002/cmdc.201800343

Cao, X., Zou, H., Cao, J., Cui, Y., Sun, S., Ren, K., Song, Z., Li, D., \& Quan, M. (2016). A candidate Chinese medicine preparation-Fructus Viticis Total Flavonoids inhibits stem-like characteristics of lung cancer stemlike cells. BMC Complementary and Alternative Medicine , 16 (1), 364. https://doi.org/10.1186/s12906016-1341-4

Chang, J. C. (2016). Cancer stem cells: Role in tumor growth, recurrence, metastasis, and treatment resistance. Medicine ,95 , S20-S25. https://doi.org/10.1097/MD.0000000000004766

Chen, L., Chan, L. S., Lung, H. L., Yip, T. T. C., Ngan, R. K. C., Wong, J. W. C., Lo, K. W., Ng, W. T., Lee, A. W. M., Tsao, G. S. W., Lung, M. L., \& Mak, N. K. (2019). Crucifera sulforaphane (SFN) inhibits the growth of nasopharyngeal carcinoma through DNA methyltransferase 1 (DNMT1)/Wnt inhibitory factor 1 (WIF1) axis. Phytomedicine ,63 , 153058. https://doi.org/10.1016/j.phymed.2019.153058

Chiu, S.-C., Chiu, T.-L., Huang, S.-Y., Chang, S.-F., Chen, S.-P., Pang, C.-Y., \& Hsieh, T.-F. (2017). Potential therapeutic effects of N-butylidenephthalide from Radix Angelica Sinensis (Danggui) in human bladder cancer cells. BMC Complementary and Alternative Medicine ,17 (1), 523. https://doi.org/10.1186/s12906017-2034-3

Cianciosi, D., Varela-Lopez, A., Forbes-Hernandez, T. Y., Gasparrini, M., Afrin, S., Reboredo-Rodriguez, P., Zhang, J., Quiles, J. L., Nabavi, S. F., Battino, M., \& Giampieri, F. (2018). Targeting molecular pathways in cancer stem cells by natural bioactive compounds.Pharmacological Research , 135 , 150-165. https://doi.org/10.1016/j.phrs.2018.08.006

Deng, S., Wong, C. K. C., Lai, H.-C., \& Wong, A. S. T. (2017). Ginsenoside-Rb1 targets chemotherapyresistant ovarian cancer stem cells via simultaneous inhibition of Wnt/ $\beta$-catenin signaling and epithelial-tomesenchymal transition. Oncotarget , 8 (16), 25897-25914. https://doi.org/10.18632/oncotarget.13071

Elkady, A. I. (2019). Targeting prostate cancer cell proliferation, stemness and metastatic potential using Costus speciosus derived phytochemicals. American Journal of Translational Research ,11 (4), 2550-2569. 
El-Merahbi, R., Liu, Y.-N., Eid, A., Daoud, G., Hosry, L., Monzer, A., Mouhieddine, T. H., Hamade, A., Najjar, F., \& Abou-Kheir, W. (2014). Berberis libanotica Ehrenb Extract Shows Anti-Neoplastic Effects on Prostate Cancer Stem/Progenitor Cells. PLoS ONE , 9 (11), e112453. https://doi.org/10.1371/journal.pone.0112453

Fan, Z., Xue, W., Dou, M., Li, L., Lu, J., Ma, B., Deng, X., Zhang, M., Zhai, Y., Wang, S., \& Zhao, J. (2018). Bushenshugan Formula Attenuates the Development of Lung Cancer by Inhibiting Epithelial-Mesenchymal Transition. Cellular Physiology and Biochemistry , 47 (5), 1977-1988. https://doi.org/10.1159/000491466

Giacomelli, C., Daniele, S., Natali, L., Iofrida, C., Flamini, G., Braca, A., Trincavelli, M. L., \& Martini, C. (2017). Carnosol controls the human glioblastoma stemness features through the epithelial-mesenchymal transition modulation and the induction of cancer stem cell apoptosis. Scientific Reports , 7 (1), 15174. https://doi.org/10.1038/s41598-017-15360-2

Gupta, P. K., Dharanivasan, G., Misra, R., Gupta, S., \& Verma, R. S. (2020). Nanomedicine in cancer stem cell therapy. In: Saxena S., Khurana S. (eds) NanoBiomedicine. Springer, Singapore. https://doi.org/10.1007/978-981-32-9898-9_4

Hemmings, B. A., \& Restuccia, D. F. (2012). PI3K-PKB/Akt Pathway. Cold Spring Harbor Perspectives in Biology , 4 (9), a011189-a011189. https://doi.org/10.1101/cshperspect.a011189

Heng, W. S., \& Cheah, S.-C. (2020). Chelerythrine Chloride Downregulates $\beta$-Catenin and Inhibits Stem Cell Properties of Non-Small Cell Lung Carcinoma. Molecules , 25 (1), 224. https://doi.org/10.3390/molecules25010224

Hermawan, A., \& Putri, H. (2018). Current report of natural product development against breast cancer stem cells. The International Journal of Biochemistry \& Cell Biology , 104 , 114-132. https://doi.org/10.1016/j.biocel.2018.09.012

Hoesel, B., \& Schmid, J. A. (2013). The complexity of NF-xB signaling in inflammation and cancer. Molecular Cancer , 12 (1), 86. https://doi.org/10.1186/1476-4598-12-86

Holohan, C., Van Schaeybroeck, S., Longley, D. B., \& Johnston, P. G. (2013). Cancer drug resistance: An evolving paradigm. Nature Reviews Cancer , 13 (10), 714-726. https://doi.org/10.1038/nrc3599

Hu, C., Li, M., Guo, T., Wang, S., Huang, W., Yang, K., Liao, Z., Wang, J., Zhang, F., \& Wang, H. (2019). Anti-metastasis activity of curcumin against breast cancer via the inhibition of stem cell-like properties and EMT. Phytomedicine , 58 , 152740. https://doi.org/10.1016/j.phymed.2018.11.001

Huynh, D. L., Koh, H., Chandimali, N., Zhang, J. J., Kim, N., Kang, T. Y., Ghosh, M., Gera, M., Park, Y.H., Kwon, T., \& Jeong, D. K. (2019). BRM270 Inhibits the Proliferation of CD44 Positive Pancreatic Ductal Adenocarcinoma Cells via Downregulation of Sonic Hedgehog Signaling.Evidence-Based Complementary and Alternative Medicine ,2019 , 1-8. https://doi.org/10.1155/2019/8620469

Jiang, F., Li, Y., Mu, J., Hu, C., Zhou, M., Wang, X., Si, L., Ning, S., \& Li, Z. (2016). Glabridin inhibits cancer stem cell-like properties of human breast cancer cells: An epigenetic regulation of miR-148a/SMAd2 signaling: GLA INHIBITS CSC-LIKE PROPERTIES VIA mIR-148a.Molecular Carcinogenesis , 55 (5), 929-940. https://doi.org/10.1002/mc.22333

Jobani, B. M., Najafzadeh, N., Mazani, M., Arzanlou, M., \& Vardin, M. M. (2018). Molecular mechanism and cytotoxicity of allicin and all-trans retinoic acid against CD44+ versus CD117+ melanoma cells.Phytomedicine , 48 , 161-169. https://doi.org/10.1016/j.phymed.2018.05.013

Kamalidehghan, B., Ahmadipour, F., Ibrahim Noordin, M., Mohan, S., Arya, A., Paydar, M., Yeng, L. C., Keong, Y. S., Ebrahimi Nigjeh, S., Fani, S., Chung, L. Y., Aspollah Sukari, M., \& Firoozi, M. (2015). Koenimbin, a natural dietary compound of Murraya koenigii (L) Spreng: Inhibition of MCF7 breast cancer cells and targeting of derived MCF7 breast cancer stem cells (CD44+/CD24-/low): an in vitro study. Drug Design, Development and Therapy, 1193. https://doi.org/10.2147/DDDT.S72127 
Kamalidehghan, B., Ghafouri-Fard, S., Motevaseli, E., \& Ahmadipour, F. (2018). Inhibition of human prostate cancer (PC-3) cells and targeting of PC-3-derived prostate cancer stem cells with koenimbin, a natural dietary compound from Murraya koenigii (L) Spreng. Drug Design, Development and Therapy , Volume 12 , 1119-1133. https://doi.org/10.2147/DDDT.S156826

Karamboulas, C., \& Ailles, L. (2013). Developmental signaling pathways in cancer stem cells of solid tumors. Biochimica et Biophysica Acta (BBA) - General Subjects , 1830 (2), 2481-2495. https://doi.org/10.1016/j.bbagen.2012.11.008

Kaur, G., Sharma, P., Dogra, N., \& Singh, S. (2018). Eradicating Cancer Stem Cells: Concepts, Issues, and Challenges. Current Treatment Options in Oncology , 19 (4), 20. https://doi.org/10.1007/s11864-018-0533-1

Khan, A. Q., Ahmed, E. I., Elareer, N., Fathima, H., Prabhu, K. S., Siveen, K. S., Kulinski, M., Azizi, F., Dermime, S., Ahmad, A., Steinhoff, M., \& Uddin, S. (2020). Curcumin-Mediated Apoptotic Cell Death in Papillary Thyroid Cancer and Cancer Stem-Like Cells through Targeting of the JAK/STAT3 Signaling Pathway. International Journal of Molecular Sciences , 21 (2), 438. https://doi.org/10.3390/ijms21020438

Kim, H., Yu, Y., Choi, S., Lee, H., Yu, J., Lee, J.-H., \& Kim, W.-Y. (2019). Evodiamine Eliminates Colon Cancer Stem Cells via Suppressing Notch and Wnt Signaling. Molecules , 24 (24), 4520. https://doi.org/10.3390/molecules24244520

Kumar, G., Farooqui, M., \& Rao, C. V. (2018). Role of Dietary Cancer-Preventive Phytochemicals in Pancreatic Cancer Stem Cells. Current Pharmacology Reports , 4 (4), 326-335. https://doi.org/10.1007/s40495018-0145-2

Kuşoğlu, A., \& Biray Avcı, Ç. (2019). Cancer stem cells: A brief review of the current status. Gene , 681 , 80-85. https://doi.org/10.1016/j.gene.2018.09.052

Leong, K. H., Mahdzir, M. A., Din, M. F. M., Awang, K., Tanaka, Y., Kulkeaw, K., Ishitani, T., \& Sugiyama, D. (2017). Induction of intrinsic apoptosis in leukaemia stem cells and in vivo zebrafish model by betulonic acid isolated from Walsura pinnata Hassk (Meliaceae).Phytomedicine , 26 , 11-21. https://doi.org/10.1016/j.phymed.2016.12.018

Li, S.-H., Fu, J., Watkins, D. N., Srivastava, R. K., \& Shankar, S. (2013). Sulforaphane regulates selfrenewal of pancreatic cancer stem cells through the modulation of Sonic hedgehog-GLI pathway.Molecular and Cellular Biochemistry , 373 (1-2), 217-227. https://doi.org/10.1007/s11010-012-1493-6

Li, W., Zhang, Q., Chen, K., Sima, Z., Liu, J., Yu, Q., \& Liu, J. (2019). 2-Ethoxystypandrone, a novel small-molecule STAT3 signaling inhibitor from Polygonum cuspidatum, inhibits cell growth and induces apoptosis of HCC cells and HCC Cancer stem cells. BMC Complementary and Alternative Medicine , 19 (1), 38. https://doi.org/10.1186/s12906-019-2440-9

Lin, C.-S., Bamodu, O. A., Kuo, K.-T., Huang, C.-M., Liu, S.-C., Wang, C.-H., Tzeng, Y.-M., Chao, T.Y., \& Yeh, C.-T. (2018). Investigation of ovatodiolide, a macrocyclic diterpenoid, as a potential inhibitor of oral cancer stem-like cells properties via the inhibition of the JAK2/STAT3/JARID1B signal circuit. Phytomedicine , 46 , 93-103. https://doi.org/10.1016/j.phymed.2018.04.016

Liu, J., Wang, P., Xue, Y., Li, Z., Qu, C., \& Liu, Y. (2015). Enhanced antitumor effect of shikonin by inhibiting Endoplasmic Reticulum Stress via JNK/c-Jun pathway in human glioblastoma stem cells.Biochemical and Biophysical Research Communications ,466 (1), 103-110. https://doi.org/10.1016/j.bbrc.2015.08.115

Liu, S.-C., Huang, C.-M., Bamodu, O. A., Lin, C.-S., Liu, B.-L., Tzeng, Y.-M., Tsai, J.-T., Lee, W.-H., \& Chen, T.-M. (2019). Ovatodiolide suppresses nasopharyngeal cancer by targeting stem cell-like population, inducing apoptosis, inhibiting EMT and dysregulating JAK/STAT signaling pathway. Phytomedicine , 56 , 269-278. https://doi.org/10.1016/j.phymed.2018.05.007

Makena, M. R., Ranjan, A., Thirumala, V., \& Reddy, A. P. (2020). Cancer stem cells: Road to therapeutic resistance and strategies to overcome resistance. Biochimica et Biophysica Acta (BBA) - Molecular Basis of 
Disease , 1866 (4), 165339. https://doi.org/10.1016/j.bbadis.2018.11.015

Matsui, W. H. (2016). Cancer stem cell signaling pathways:Medicine , 95 , S8-S19. https://doi.org/10.1097/MD.0000000000004765

Naveen, C. R., Gaikwad, S., \& Agrawal-Rajput, R. (2016). Berberine induces neuronal differentiation through inhibition of cancer stemness and epithelial-mesenchymal transition in neuroblastoma cells.Phytomedicine, 23 (7), 736-744. https://doi.org/10.1016/j.phymed.2016.03.013

Nistico, P., Bissell, M. J., \& Radisky, D. C. (2012). Epithelial-Mesenchymal Transition: General Principles and Pathological Relevance with Special Emphasis on the Role of Matrix Metalloproteinases. Cold Spring Harbor Perspectives in Biology ,4 (2), a011908-a011908. https://doi.org/10.1101/cshperspect.a011908

Oh, J., Hlatky, L., Jeong, Y.-S., \& Kim, D. (2016). Therapeutic Effectiveness of Anticancer Phytochemicals on Cancer Stem Cells. Toxins , 8 (7), 199. https://doi.org/10.3390/toxins8070199

Pak, P. J., Kang, B. H., Park, S. H., Sung, J. H., Joo, Y. H., Jung, S. H., \& Chung, N. (2016). Antitumor effects of herbal mixture extract in the pancreatic adenocarcinoma cell line PANC1. Oncology Reports, 36 (5), 2875-2883. https://doi.org/10.3892/or.2016.5067

Qi, F., Wei, L., Shen, A., Chen, Y., Lin, J., Chu, J., Cai, Q., Pan, J., \& Peng, J. (2016). Pien Tze Huang inhibits the proliferation, and induces the apoptosis and differentiation of colorectal cancer stem cells via suppression of the Notch1 pathway. Oncology Reports ,35 (1), 511-517. https://doi.org/10.3892/or.2015.4378

Salehi, B., Varoni, E. M., Sharifi-Rad, M., Rajabi, S., Zucca, P., Iriti, M., \& Sharifi-Rad, J. (2019). Epithelialmesenchymal transition as a target for botanicals in cancer metastasis. Phytomedicine ,55 , 125-136. https://doi.org/10.1016/j.phymed.2018.07.001

Seo, E.-J., Wiench, B., Hamm, R., Paulsen, M., Zu, Y., Fu, Y., \& Efferth, T. (2015). Cytotoxicity of natural products and derivatives toward MCF-7 cell monolayers and cancer stem-like mammospheres. Phytomedicine , 22 (4), 438-443. https://doi.org/10.1016/j.phymed.2015.01.012

Sinha, N., Meher, B. R., Naik, P. P., Panda, P. K., Mukhapadhyay, S., Maiti, T. K., \& Bhutia, S. K. (2019). P73 induction by Abrus agglutinin facilitates Snail ubiquitination to inhibit epithelial to mesenchymal transition in oral cancer. Phytomedicine , 55 , 179-190. https://doi.org/10.1016/j.phymed.2018.08.003

Sinha, N., Panda, P. K., Naik, P. P., Maiti, T. K., \& Bhutia, S. K. (2017). Abrus agglutinin targets cancer stem-like cells by eliminating self-renewal capacity accompanied with apoptosis in oral squamous cell carcinoma. Tumor Biology , 39 (5), 101042831770163. https://doi.org/10.1177/1010428317701634

Soltanian, S., Riahirad, H., Pabarja, A., Jafari, E., \& Khandani, B. K. (2018). Effect of Cinnamic acid and FOLFOX in diminishing side population and downregulating cancer stem cell markers in colon cancer cell line HT-29. DARU Journal of Pharmaceutical Sciences ,26 (1), 19-29. https://doi.org/10.1007/s40199-018$0210-8$

Song, L., Chen, X., Wang, P., Gao, S., Qu, C., \& Liu, L. (2018). Effects of baicalein on pancreatic cancer stem cells via modulation of sonic Hedgehog pathway. Acta Biochimica et Biophysica Sinica ,50 (6), 586-596. https://doi.org/10.1093/abbs/gmy045

Steinbichler, T. B., Dudás, J., Skvortsov, S., Ganswindt, U., Riechelmann, H., \& Skvortsova, I.-I. (2018). Therapy resistance mediated by cancer stem cells. Seminars in Cancer Biology ,53 , 156-167. https://doi.org/10.1016/j.semcancer.2018.11.006

Stine, R. R., \& Matunis, E. L. (2013). JAK-STAT Signaling in Stem Cells. In G. Hime \& H. Abud (Eds.), Transcriptional and Translational Regulation of Stem Cells (Vol. 786, pp. 247-267). Springer Netherlands. https://doi.org/10.1007/978-94-007-6621-1_14

Su, Y., Bamodu, O. A., Tzeng, Y.-M., Hsiao, M., Yeh, C.-T., \& Lin, C.-M. (2019). Ovatodiolide inhibits the oncogenicity and cancer stem cell-like phenotype of glioblastoma cells, as well as potentiate the anticancer 
effect of temozolomide. Phytomedicine , 61 , 152840. https://doi.org/10.1016/j.phymed.2019.152840

Suman, S., Das, T. P., \& Damodaran, C. (2013). Silencing NOTCH signaling causes growth arrest in both breast cancer stem cells and breast cancer cells. British Journal of Cancer , 109 (10), 2587-2596. https://doi.org/10.1038/bjc.2013.642

Torquato, H., Goettert, M., Justo, G., \& Paredes-Gamero, E. (2017). Anti-Cancer Phytometabolites Targeting Cancer Stem Cells. Current Genomics , 18 (2), 156-174. https://doi.org/10.2174/1389202917666160803162309

Tsai, J. H., \& Yang, J. (2013). Epithelial-mesenchymal plasticity in carcinoma metastasis. Genes $\mathscr{E}$ Development , 27 (20), 2192-2206. https://doi.org/10.1101/gad.225334.113

Upadhyaya, B., Liu, Y., \& Dey, M. (2019). Phenethyl Isothiocyanate Exposure Promotes Oxidative Stress and Suppresses Sp1 Transcription Factor in Cancer Stem Cells. International Journal of Molecular Sciences , 20 (5), 1027. https://doi.org/10.3390/ijms20051027

Wang, B., Dai, Z., Yang, X.-W., Liu, Y.-P., Khan, A., Yang, Z.-F., Huang, W.-Y., Wang, X.-H., Zhao, X.-D., \& Luo, X.-D. (2018). Novel nor-monoterpenoid indole alkaloids inhibiting glioma stem cells from fruits of Alstonia scholaris. Phytomedicine , 48 , 170-178. https://doi.org/10.1016/j.phymed.2018.04.057

Wang, D., Kong, X., Li, Y., Qian, W., Ma, J., Wang, D., Yu, D., \& Zhong, C. (2017). Curcumin inhibits bladder cancer stem cells by suppressing Sonic Hedgehog pathway. Biochemical and Biophysical Research Communications , 493 (1), 521-527. https://doi.org/10.1016/j.bbrc.2017.08.158

Wang, J., Lai, Z., Chen, X., Li, D., Zhang, Y., Ma, W., Chu, Y., Shi, F., Yang, L., \& Hou, L. (2016). Effect of Compound Zhebei Granule combined with chemotherapy on surface markers of leukemia stem cell in patients with acute myeloid leukemia. Chinese Journal of Integrative Medicine , 22 (6), 438-444. https://doi.org/10.1007/s11655-015-2117-2

Wang, K., Huang, W., Sang, X., Wu, X., Shan, Q., Tang, D., Xu, X., \& Cao, G. (2020). Atractylenolide I inhibits colorectal cancer cell proliferation by affecting metabolism and stemness via AKT/mTOR signaling. Phytomedicine , 68 , 153191. https://doi.org/10.1016/j.phymed.2020.153191

Wang, L., Guo, H., Yang, L., Dong, L., Lin, C., Zhang, J., Lin, P., \& Wang, X. (2013). Morusin inhibits human cervical cancer stem cell growth and migration through attenuation of NF- $x \mathrm{~B}$ activity and apoptosis induction. Molecular and Cellular Biochemistry , 379 (1-2), 7-18. https://doi.org/10.1007/s11010-013$1621-y$

Wang, Y., Ying, X., Xu, H., Yan, H., Li, X., \& Tang, H. (2017). The functional curcumin liposomes induce apoptosis in $\mathrm{C} 6$ glioblastoma cells and $\mathrm{C} 6$ glioblastoma stem cells in vitro and in animals.International Journal of Nanomedicine, Volume 12 , 1369-1384. https://doi.org/10.2147/IJN.S124276

Wei, L., Chen, P., Chen, Y., Shen, A., Chen, H., Lin, W., Hong, Z., Sferra, T. J., \& Peng, J. (2014). Pien Tze Huang suppresses the stem-like side population in colorectal cancer cells. Molecular Medicine Reports , 9 (1), 261-266. https://doi.org/10.3892/mmr.2013.1760

Wen, Z., Feng, S., Wei, L., Wang, Z., Hong, D., \& Wang, Q. (2015). Evodiamine, a novel inhibitor of the Wnt pathway, inhibits the self-renewal of gastric cancer stem cells. International Journal of Molecular Medicine , 36 (6), 1657-1663. https://doi.org/10.3892/ijmm.2015.2383

Yadav, A. K., \& Desai, N. S. (2019). Cancer Stem Cells: Acquisition, Characteristics, Therapeutic Implications, Targeting Strategies and Future Prospects. Stem Cell Reviews and Reports , 15 (3), 331-355. https://doi.org/10.1007/s12015-019-09887-2

Yan, B. (2014). Xiaotan Sanjie decoction attenuates tumor angiogenesis by manipulating Notch-1regulated proliferation of gastric cancer stem-like cells. World Journal of Gastroenterology ,20 (36), 13105. https://doi.org/10.3748/wjg.v20.i36.13105 
Yang, J., Fang, Z., Wu, J., Yin, X., Fang, Y., Zhao, F., Zhu, S., \& Li, Y. (2016). Construction and application of a lung cancer stem cell model: Antitumor drug screening and molecular mechanism of the inhibitory effects of sanguinarine. Tumor Biology , 37 (10), 13871-13883. https://doi.org/10.1007/s13277-016-5152-5

Yang, Y., Hao, E., Pan, X., Tan, D., Du, Z., Xie, J., Hou, X., Deng, J., \& Wei, K. (2019). Gomisin M2 from Baizuan suppresses breast cancer stem cell proliferation in a zebrafish xenograft model. Aging ,11 (19), 8347-8361. https://doi.org/10.18632/aging.102323

Yanli, X., Feiye, Z., Shan, X., \& Luming, L. (2015). Anti-tumor effect of the extract from Qingyihuaji formula on pancreatic cancer by down-regulating Notch-4 and Jagged-1. Journal of Traditional Chinese Medicine , 35 (1), 77-83. https://doi.org/10.1016/S0254-6272(15)30012-1

Yao, C.-J., Han, T.-Y., Shih, P.-H., Yi, T.-Y., Lai, I.-C., Chang, K.-H., Lai, T.-Y., Chang, C.-L., \& Lai, G.-M. (2014). Elimination of Cancer Stem-Like Side Population in Human Glioblastoma Cells Accompanied with Stemness Gene Suppression by Korean Herbal Recipe MSC500. Integrative Cancer Therapies , 13 (6), 541-554. https://doi.org/10.1177/1534735414549623

Yen, C.-H., Lai, C.-C., Shia, T.-H., Chen, M., Yu, H.-C., Liu, Y.-P., \& Chang, F.-R. (2018). Gynura divaricata attenuates tumor growth and tumor relapse after cisplatin therapy in HCC xenograft model through suppression of cancer stem cell growth and Wnt/ $\beta$-catenin signalling. Journal of Ethnopharmacology , 213 , 366-375. https://doi.org/10.1016/j.jep.2017.07.019

Yoneyama, T., Arai, M. A., Sadhu, S. K., Ahmed, F., \& Ishibashi, M. (2015). Hedgehog inhibitors from Withania somnifera. Bioorganic 83 Medicinal Chemistry Letters , 25 (17), 3541-3544. https://doi.org/10.1016/j.bmcl.2015.06.081

Yousefnia, S., Naseri, D., Seyed Forootan, F., Tabatabaeian, M., Moattar, F., Ghafghazi, T., Nasr Esfahani, M. H., \& Ghaedi, K. (2020). Suppressive role of Viola odorata extract on malignant characters of mammosphere-derived breast cancer stem cells. Clinical and Translational Oncology, 22 (9), 1619-1634. https://doi.org/10.1007/s12094-020-02307-9

Yun, J. H., Kim, K.-A., Yoo, G., Kim, S. Y., Shin, J. M., Kim, J. H., Jung, S. H., Kim, J., \& Nho, C. W. (2017). Phenethyl isothiocyanate suppresses cancer stem cell properties in vitro and in a xenograft model. Phytomedicine , 30 , 42-49. https://doi.org/10.1016/j.phymed.2017.01.015

Zhan, T., Rindtorff, N., \& Boutros, M. (2017). Wnt signaling in cancer.Oncogene , 36 (11), 1461-1473. https://doi.org/10.1038/onc.2016.304

Zhang, Q., Li, X.-T., Chen, Y., Chen, J.-Q., Zhu, J.-Y., Meng, Y., Wang, X.-Q., Li, Y., Geng, S.-S., Xie, C.-F., Wu, J.-S., Zhong, C.-Y., \& Han, H.-Y. (2018). Wnt/ $\beta$-catenin signaling mediates the suppressive effects of diallyl trisulfide on colorectal cancer stem cells. Cancer Chemotherapy and Pharmacology , 81 (6), 969-977. https://doi.org/10.1007/s00280-018-3565-0

Zhou, Q., Ye, M., Lu, Y., Zhang, H., Chen, Q., Huang, S., \& Su, S. (2015). Curcumin Improves the Tumoricidal Effect of Mitomycin C by Suppressing ABCG2 Expression in Stem Cell-Like Breast Cancer Cells.PLOS ONE , 10 (8), e0136694. https://doi.org/10.1371/journal.pone.0136694

Zhu, J., Wang, S., Chen, Y., Li, X., Jiang, Y., Yang, X., Li, Y., Wang, X., Meng, Y., Zhu, M., Ma, X., Huang, C., Wu, R., Xie, C., Geng, S., Wu, J., Zhong, C., \& Han, H. (2017). MiR-19 targeting of GSK3 $\beta$ mediates sulforaphane suppression of lung cancer stem cells. The Journal of Nutritional Biochemistry , 44 , 80-91. https://doi.org/10.1016/j.jnutbio.2017.02.020 